\title{
The hemogenic endothelium: a critical source for the generation of PSC-derived hematopoietic stem and progenitor cells
}

\author{
Lucas Lange $^{1,2} \cdot$ Michael Morgan $^{1,2} \cdot$ Axel Schambach $^{1,2,3}$
}

Received: 12 August 2020 / Revised: 16 December 2020 / Accepted: 15 January 2021 / Published online: 9 February 2021

(c) The Author(s) 2021

\begin{abstract}
In vitro generation of hematopoietic cells and especially hematopoietic stem cells (HSCs) from human pluripotent stem cells (PSCs) are subject to intensive research in recent decades, as these cells hold great potential for regenerative medicine and autologous cell replacement therapies. Despite many attempts, in vitro, de novo generation of bona fide HSCs remains challenging, and we are still far away from their clinical use, due to insufficient functionality and quantity of the produced HSCs. The challenges of generating PSC-derived HSCs are already apparent in early stages of hemato-endothelial specification with the limitation of recapitulating complex, dynamic processes of embryonic hematopoietic ontogeny in vitro. Further, these current shortcomings imply the incompleteness of our understanding of human ontogenetic processes from embryonic mesoderm over an intermediate, specialized hemogenic endothelium (HE) to their immediate progeny, the HSCs. In this review, we examine the recent investigations of hemato-endothelial ontogeny and recently reported progress for the conversion of PSCs and other promising somatic cell types towards HSCs with the focus on the crucial and inevitable role of the HE to achieve the long-standing goal—to generate therapeutically applicable PSC-derived HSCs in vitro.
\end{abstract}

Keywords Hematopoietic stem cells $\cdot$ Induced pluripotent stem cells $\cdot$ Hemogenic endothelium $\cdot$ Endothelial-tohematopoietic transition

\section{Introduction}

Definitive bona fide hematopoietic stem cells (HSCs) are defined based on specific and unique hallmarks of selfrenewing cells with long-term engraftment and full multilineage reconstitution potential after transplantation in a conditioned recipient. Postnatally, HSCs reside in specialized bone marrow (BM) niches that preserve (1) HSC in a multipotent, self-renewing steady state or (2) facilitate differentiation into mature progeny via asymmetric cell divisions. HSCs form the apex of the hierarchical scheme of

Axel Schambach

schambach.axel@mh-hannover.de;

axel.schambach@childrens.harvard.edu

1 Institute of Experimental Hematology, Hannover Medical School, 30625 Hannover, Germany

2 REBIRTH, Research Center for Translational Regenerative Medicine, Hannover Medical School, 30625 Hannover, Germany

3 Division of Hematology/Oncology, Boston Children's Hospital, Harvard Medical School, Boston, MA 02115, USA adult hematopoiesis and give rise to hematopoietic progenitor cells (HPCs), which, in contrast to HSCs, are characterized by limited self-renewal, engraftment and lineage potential. HSCs provide a constant supply of all hematopoietic cells throughout the entire lifetime of an organism. These hallmarks make HSCs an invaluable cell source and HSC transplantation has become a standard for cell replacement therapy to treat a variety of hematological diseases and malignancies $[1,2]$. While murine HSC ex vivo expansion is well established, ex vivo long-term expansion of functional human HSCs is still challenging [3]. This poor ex vivo expansion leads to relatively low quantity and quality of functional human HSCs. Furthermore, immunological incompatibilities are another limiting factor for the use of HSCs for transplantation and necessitate human leukocyte antigen (HLA) matching between donors and recipients [1, 2].

Advances in the cultivation, generation and differentiation of pluripotent stem cells (PSCs) and especially the reprogramming of somatic cells into induced pluripotent stem cells (iPSCs) $[4,5]$ would overcome many of these limitations and represent a potential paradigm shift in regenerative 
medicine. Generally, iPSCs are generated by ectopic expression of the transcription factors (TFs) OCT4, SOX2, MYC and KLF4 [4] in somatic and well-accessible cells. iPSCs have an indefinite proliferation potential in culture and the capacity to be differentiated into all somatic cell types. These properties offer a potential use of the iPSC technology for personalized and autologous cell-based therapies in a variety of diseases. Improved genome editing technologies further enhance the potential use of iPSC as powerful tools in basic research, disease modeling, drug screening as well as to mimic ontogenetic and pathophysiological processes in vitro [6]. However, the clinical utility of iPSC-derived cell products is heavily dependent on several factors, including the differentiation techniques, cost-effective scale-up to produce adequate numbers of therapeutic cells and, most strikingly, on the safety and functionality of the final cell product.

Despite these advances and vigorous research over the last decades, de novo generation of PSC-derived functionally transplantable HSCs in vitro remains challenging and a high priority for hematology and regenerative medicine. PSC-derived functional HSCs generated under experimental conditions had reconstitution and engraftment potential as shown by in vivo teratoma formation approaches [7, 8], providing evidence for the HSC capacity of PSCs. However, these approaches highly rely on specific, instructive niches and cell-cell interactions and are far from defined conditions. Two major approaches are predominantly used for in vitro differentiations: (1) use of defined cell-extrinsic factors for directed differentiation (e.g., defined morphogens, serum, conditioned media or co-culture systems) and/ or (2) direct conversion and forward programming through TF-mediated cell fate determination. Both strategies rely on recapitulating crucial aspects of ontogenetic processes and require a detailed understanding of critical stages of early hemato-endothelial development. To more thoroughly explore these different strategies, it is important to first discuss primitive and definitive hematopoiesis.

\section{Embryonic hematopoiesis in mammals: drawing lessons from development}

The hematopoietic ontogeny is complex and encompasses temporal and spatial patterns. These spatiotemporal differences are most commonly represented as a simplified twostage model of successive waves of primitive (first wave) and definitive (second and third waves) hematopoiesis, that differ in their hematopoietic potential (Fig. 1).

\section{Primitive hematopoietic wave}

The primitive wave is considered as the initial program of embryonic hematopoiesis. Shortly after mesodermal

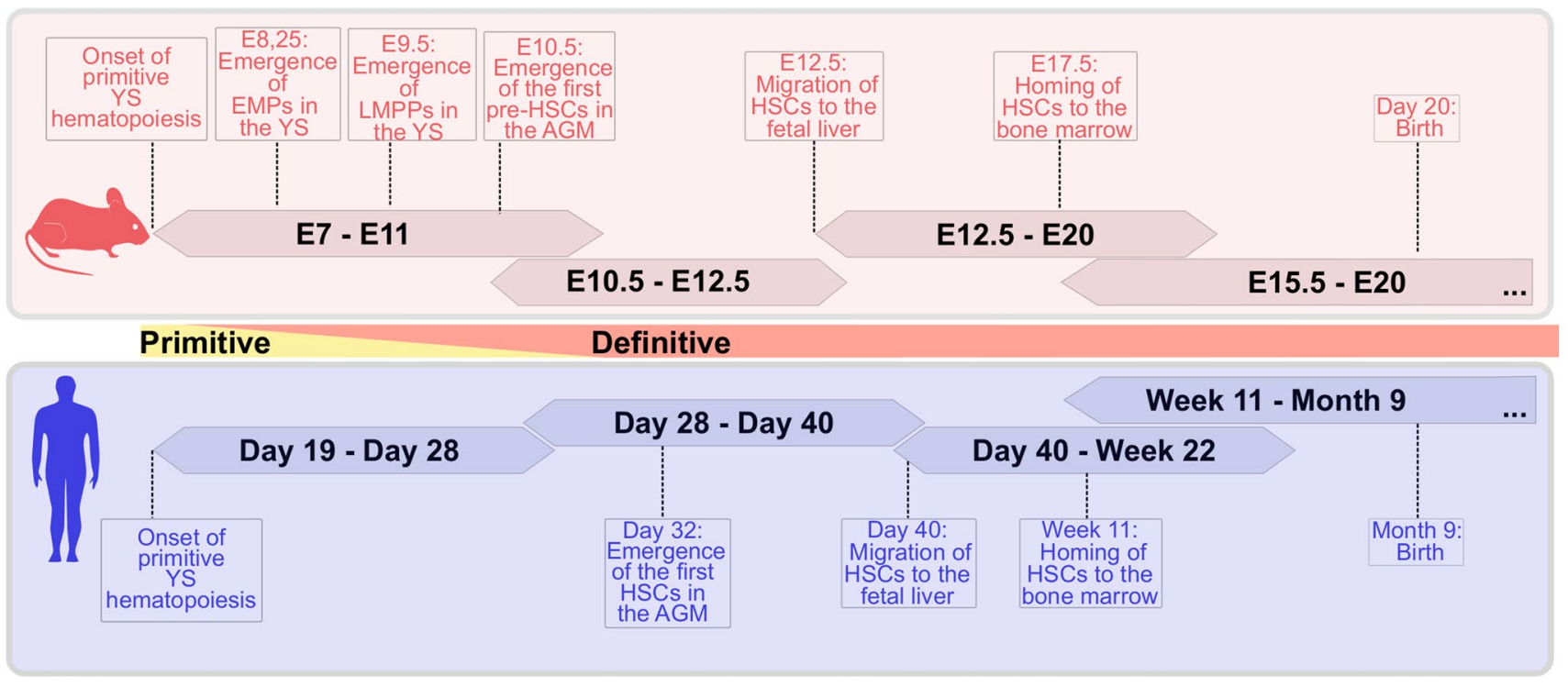

Fig. 1 Simplified two-stage model of the spatiotemporal organization of embryonic hematopoiesis in mice and humans. Scheme of the timing and emergence of hematopoietic cells during hematopoietic ontogeny of mice (in red) and humans (in blue). Primitive hematopoiesis is the initial wave in the extraembryonic yolk sac (YS), followed by the emergence of definitive erythro-myeloid progenitors (EMPs) and lymphoid-primed progenitors (LMPPs) in the extraem- bryonic compartment. The first HSCs arise in the intraembryonic aorta-gonad-mesonephros region (AGM). The AGM-derived, immature, pre-HSCs migrate and colonize the fetal liver for a maturation and expansion step. After this expansion, the mature HSCs mobilize to the bone marrow, where they reside throughout the adult life after birth 
formation, cells of the primitive streak form the extraembryonic yolk sack (YS) and the vascular plexus, containing the blood islands [9]. The primitive hematopoietic program is initiated between embryonic day 7 (E7) and E8.5 within the blood islands of the mouse embryo [10] and during the third week in the human ontogeny [11] (Fig. 1). This hematopoietic wave is highly restricted, with the primary function to produce primitive erythrocytes, macrophages [10] and megakaryocytes [12], independent of HSCs.

\section{Definitive hematopoietic waves}

In the mouse embryo, between E8.25 and E10, YS hematopoiesis also gives rise to multipotent progenitors, with definitive erythrocytes, megakaryocytes and granulocyte-macrophage progenitors, and is broadly termed EMPhematopoiesis (erythro-myeloid hematopoiesis) as the second wave of hematopoiesis $[10,13,14]$. In the later stage of the second wave of murine hematopoiesis and overlapping with the EMP-hematopoiesis, extraembryonic YS hematopoiesis also gives rise to multipotent progenitors with lymphoid (NK, B and T cell) potential [15-17]. Based on their lymphoid potential, these progenitors have been named lymphoid-primed progenitors (LMPP) (Fig. 1).

This transient second hematopoietic wave produces multipotent progenitors (EMP, LMPP) with several blood lineages and definitive erythrocytes, independent of the primitive hematopoietic wave. Therefore, this wave can be considered as the onset of definitive hematopoiesis $[18,19]$, although the origin of these hematopoietic cells is the YS and prior to the activity of HSCs. Lineage-tracing studies further provided evidence for the HSC-independent lymphoid progenitor potential of the YS. These progenitors demonstrated lymphoid and myeloid potential, but lacked erythro-megakaryocytic potential and were traced back to E9.5 in the extraembryonic YS. These data suggest the existence of a lympho-myeloid progenitor that precedes HSC development [20,21]. In contrast to the murine embryo, de novo generation of YS-derived LMPPs was not observed before the onset of circulation in the extraembryonic YS during human hematopoietic ontogeny $[22,23]$. This further indicates significant evolutionary differences between human and mouse embryonic hematopoiesis.

The defining quality of the third wave of hematopoiesis is the generation of bona fide HSCs with the capacity to engraft adult recipients.

\section{Embryonic origin of HSCs}

Transplantation experiments of cells acquired from different developmental stages of murine hematopoietic cells showed that the first occurrence of definitive HSC with the capacity to engraft adult recipients arise between E10.5 and E11.5
[24] and in the human embryo at day 32 of gestation [25] (Fig. 1), independently of the YS hematopoiesis [26]. At this time point, a splanchnopleural mesoderm-derived, intraembryonic, definitive hematopoietic site was identified as the aorta-gonad-mesonephros (AGM) [27, 28] region, particularly the dorsal aorta (DA) [29-31], which is probably the best-studied site for de novo HSCs generation. Although the DA is an origin for HSC emergence, the numbers of HSCs in the AGM region are low [32-34], and HSCs are only present transiently at this site. Therefore, the AGM is not considered to be a major site for HSC expansion. Shortly after HSC emergence, AGM-derived HSC migrate and colonize different fetal hematopoietic sites, where they mature and expand. In mouse, cells with multi-lineage repopulation activity were first detected in the fetal liver (FL) at E12, concomitant with a dramatic expansion and formation of an FL HSC pool [35], until mobilization of HSCs out of the FL towards other hematopoietic tissues like thymus and finally, the bone marrow [36]. Although several different sites with hematopoietic activity have been described during mammalian ontogeny, the primary origin(s) of hematopoietic cells and, in particular, the embryonic ancestor of HSCs remain controversial and a current area of extensive research.

\section{The hemogenic endothelium: an endothelial link to hematopoietic development and the womb of definitive HSCs}

More than 100 years ago, Sabin observed aggregates of hematopoietic cells budding from a layer of endothelial cells in chick embryos [37]. This observation and the concomitant temporal and spatial emergence of endothelial and hematopoietic cells during vertebrate ontogeny led to the hypothesis of a close developmental correlation between endothelial and hematopoietic cells. This hypothesis was further supported and validated in later experiments. Ex vivo culture of murine $\mathrm{KDR}^{+}$(kinase insert domain-containing receptor; vascular endothelial growth factor receptor 2) endothelial cells gave rise to multi-lineage hematopoietic cells with reconstitution potential after intrahepatic injection into conditioned newborn recipient mice [38]. Lineage-tracing studies tracked the fate of $\mathrm{CD} 144^{+}$endothelial cells that gave rise to multi-lineage hematopoietic cells in vivo [39]. Time-lapse confocal imaging of murine E10.5 DA validated the endothelial origin and showed a dynamic emergence of hematopoietic cells, directly sprouting from ventral aortic endothelial cells [40]. These elegant experiments demonstrated that hematopoietic cells, including HSCs, arise through an intermediate endothelial state known as hemogenic endothelium (HE). 


\section{HE surface markers: murine and human}

By definition, HE is a transient, specialized endothelium with the capacity to generate hematopoietic cells through a gradual process of endothelial-to-hematopoietic transition (EHT) [41]. So far, no unique surface marker has been described to identify HE. Murine endothelium with hemogenic potential are generally identified retrospectively by the potential to give rise to hematopoietic cells and are often characterized by co-expressed surface markers CD144, CD31, KDR, CD117, CD34, and the lack of hematopoieticassociated markers such as CD41, CD45 and Ter-119 [42, 43] (Fig. 2). A similar immunophenotype was also found on human PSC-derived HE with co-expression patterns of surface markers CD144, CD31, KDR, CD117 and CD34 and lack of CD43 [44-46]. In combination with these markers, the lack of CD73 expression was identified to demarcate endothelium with hemogenic potential from non-hemogenic endothelium. During the transition from endothelial cells towards a hematopoietic cell type, endothelial cells gradually lose endothelial characteristics, and concomitantly acquire a hematopoietic phenotype and morphology [41, 47]. In humans, the early emerged hematopoietic committed cells can be identified based on the surface markers CD43, CD34, CD144, CD117, CD90, CD45, CD105, low CD38, and the lack of CD45RA (Fig. 2) [31, 46, 48, 49].

Although the concept of the HE as a precursor of hematopoietic cells is best studied in the AGM region, several other endothelial sites with hemogenic potential have been described in the YS, placenta, major arteries (umbilical and vitelline arteries) and head [30,50-57]. It was shown that lymphoid cells and, more strikingly, HSCs are predominantly derived from arterial-type hemogenic endothelium [58-61]. However, are all of these hemogenic cells identical, or are there functional, transcriptional, and/or developmental heterogeneities among HE cells?

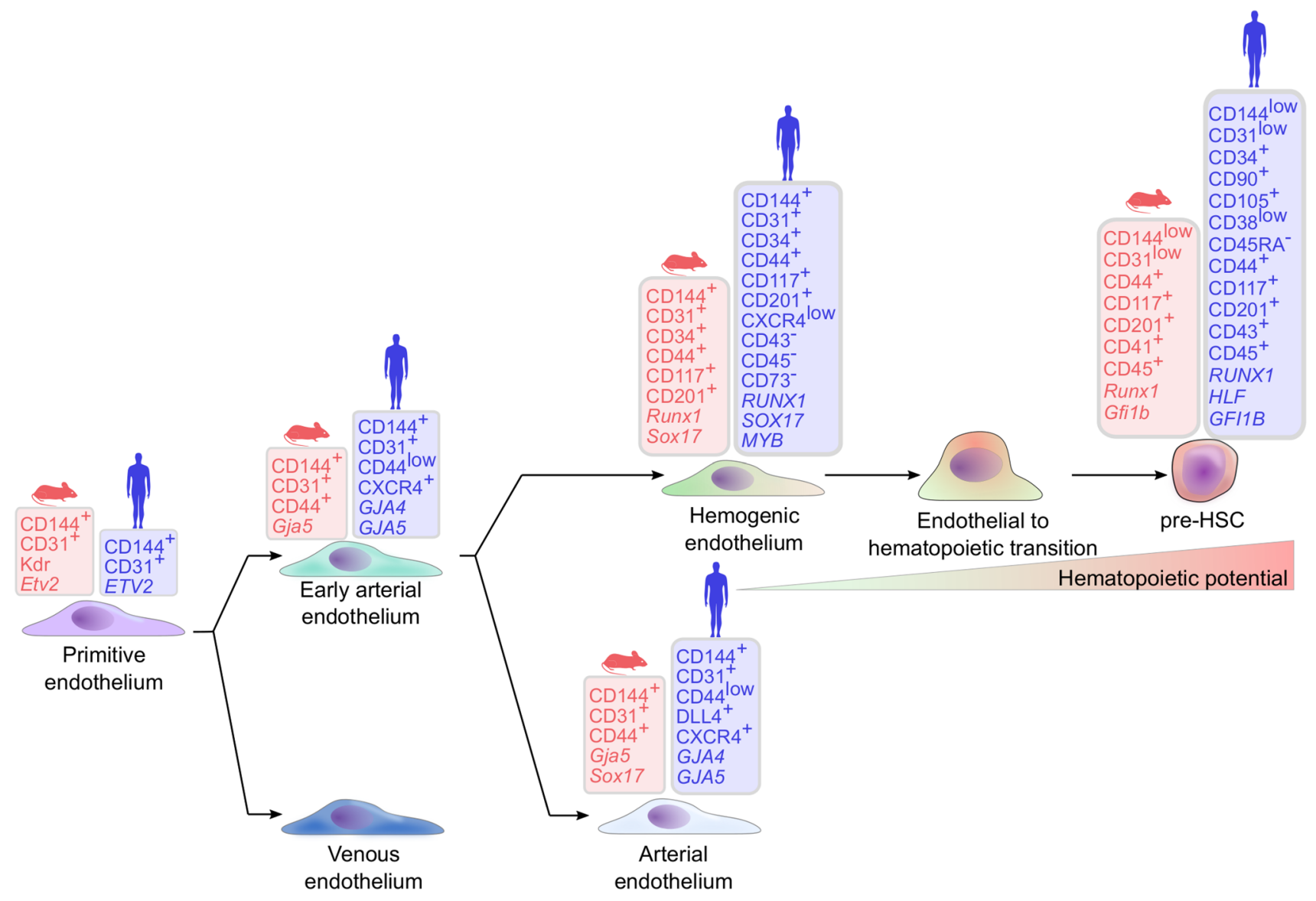

Fig. 2 Simplified model of HSC emergence through different intermediate endothelial stages in mice and humans. Two major fate decisions precede HSC emergence in a dynamic process. Primitive endothelial cells first acquire an early arterial fate, followed by hemogenic endothelial specification, segregated from mature arterial endothelium. The early arterial endothelium-derived hemogenic endothelium (HE) gives rise to pre-HSCs through a gradual endothe- lial to hematopoietic transition. All intermediate developmental stages can be segregated based on their functionality and different gene expression and surface marker profiles. The phenotype of the different developmental stages is based on a combination of PSC differentiation, in vivo lineage tracing and single cell transcriptome fate mapping. Figure includes data from references $[31,41-49,64,71,73$, $78,112]$ 


\section{Signal transduction and gene expression patterns in HE to HSC transition}

Notch signaling has a central role during HSC emergence, endothelial development, and arterial identity of the endothelium [62-67]. Notch knockout studies in zebrafish demonstrated that primitive hematopoiesis is independent of Notch signaling. Definitive hematopoiesis and HSC emergence necessitated Notch signaling and were linked to runxl expression as a direct downstream target [68]. Similarly, HE demonstrated pre-existing arterial endothelial characteristics, suggesting an arterial endothelium as a direct precursor [69]. The hematopoietic commitment of the arterialized endothelium was initiated by runxl expression and, as a consequence, resulted in downregulation of runxlregulated arterial genes like sox 17 or the Notch ligand dll4 in zebrafish [69]. Interestingly, the dosage of Notch signaling and the balance between Notch-Dll4 and Notch-Jag 1 signaling was described to be crucial for either arterial endothelial or hemogenic cell fate in mice [70]. High Notch-signaling activity through Dll4 favors arterial endothelial specification, whereas low Notch signaling through Jag 1 activates hematopoietic genes and commitment [70]. In the same study, Jag1-induced microRNA expression was described, which might posttranscriptionally regulate the endothelialassociated gene expression [70].

Single-cell RNA sequencing of different developmental stages of the human AGM validated the arterial origin and mapped the developmental fate of HSCs through an arterial endothelium, and an intermediate arterialized HE [71]. This approach identified an ETV2-expressing endothelial precursor, which independently gave rise to both arterial and venous endothelium with distinct hemogenic potential. The human AGM region HE exhibited typical expression of genes, associated with arterial-type endothelium (e.g., GJA5, GJA4, HEY2, CXCR4, DLL4, MECOM, and HES4), including crucial genes of the NOTCH-signaling pathway and was almost entirely absent of venous characteristics. Along with arterial HE differentiation, expression levels of EMCN, RUNXITI and PROCR were increased, which decreased upon hematopoietic commitment, concomitant with upregulation of PTPRC, ANGPTI and SPINK2 in emerging HSCs [71]. Interestingly, the same study identified the surface marker CD44, a marker previously described to be expressed in the inner layer of endothelial cells in the DA [72], to be almost explicitly expressed on arterial endothelial cells with hemogenic potential, but seldom on venous HE [71]. Thus, CD44 might be a suitable marker to characterize the developmental stages and identify arterialized HE and HSC emergence for in vitro differentiation. In line with this approach, single cell transcriptome analyses used to map the fate of endothelial cells towards hematopoietic cells in mid-gestational mice AGM regions between E9.5 and E11 similarly demonstrated an early arterial endothelial precursor of HE [73]. Computational prediction of their singlecell RNA-sequencing data revealed two bifurcations and fate decisions of endothelial cells during HE specification, which were distinguishable by their gene expression (Fig. 2). The first fate decision occurred in primitive endothelial cells between a venous endothelial phenotype and a primitive arterial-type endothelium. Later, the early arterial endothelium acquired either a mature arterial phenotype (late arterial endothelial cells) or became HE with the capacity to generate committed HSC precursors (pre-HSC) [73] (Fig. 2). PreHSCs can be subdivided into pro-HSCs, type I pre-HSCs and type II pre-HSCs based upon their maturation stage and engraftment capability [61, 74-76]. Surprisingly, the same study described a bi-potent rare, putative committed preHSC capable of endothelial and hematopoietic specification $[73,77]$. This finding underlines the dynamic progress of this transition and raises the question at which time point the final commitment of pre-HSCs occurs. Similar to the transient upregulation of PROCR (also known as EPCR or CD201) expression upon hemogenic fate specification in the human AGM [71], CD201 marked murine HE populations and pre-HSCs $[73,78]$ and could be a putative marker for in vitro-derived HSC-primed, arterialized HE. Interestingly, EPCR was further found to mark engraftment- and reconstitution-competent HSCs derived from human cord blood CD34 ${ }^{+}$cells that were expanded with UM171 [79].

\section{Emergence of HSCs from the HE}

In vivo, the vast majority of the endothelial cells within the hematopoietic sites during ontogeny are vascular endothelial cells without hemogenic potential. Only small subsets of endothelial cells demonstrate the capacity for de novo hematopoietic cell generation. During murine embryogenesis, hematopoietic cells arise through an intermediate HE between E7.25 [55] to shortly after birth [80]. During the EHT process in the DA of the E10.5 AGM, endothelial cells and the derived hematopoietic cells are organized in clusters, attached to an endothelial layer and bud into the lumen of the vessel (Fig. 3) [81-83]. For the DA, these clusters are later referred to as intra-aortic hematopoietic clusters (IAHCs) and the formation is highly conserved and described for several vertebrate species [30, 84, 85], including humans [49]. Not all hematopoietic cells that arise in the AGM region through IAHCs are bona fide mature HSCs. In mouse, IAHCs consist of an HSC precursor (type II pre-HSC) and already committed hematopoietic progenitors. However, in mice, the majority of the IAHC probably comprise very immature pre-HSC (type I or pro-HSC), yet incapable of long-term engraftment or multi-lineage reconstitution of neonate recipients [74-76], but able to progressively mature towards bona fide HSCs within different hematopoietic sites 


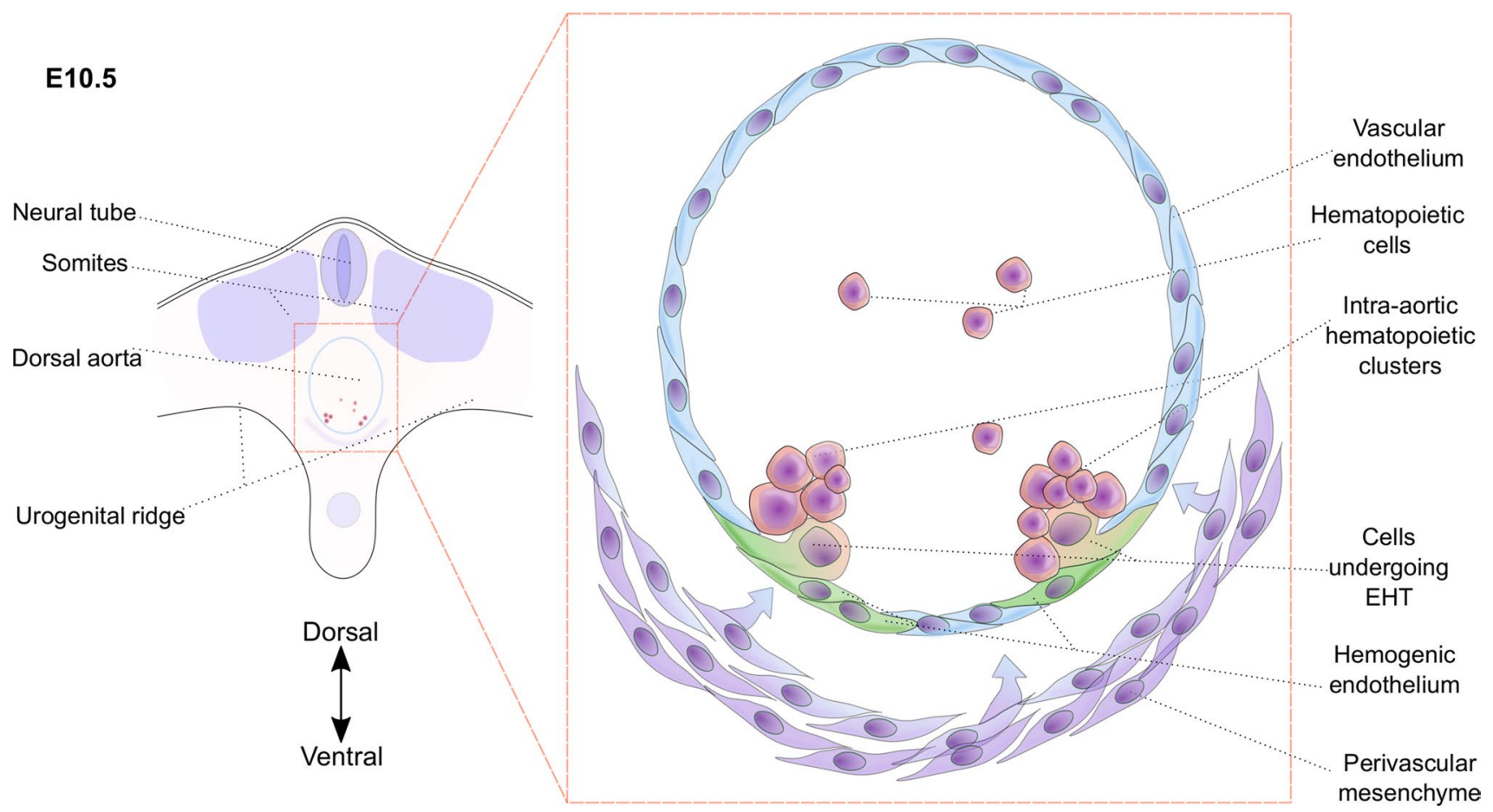

Fig. 3 Hemogenic fate specification and HSC emergence from hemogenic endothelium (HE). a Schematic cross-section through the murine E10.5 aorta-gonad-mesonephros (AGM) region. The dorsal aorta (DA) is boxed (red dashed box) and magnified to visualize the cell types involved in AGM hematopoiesis. Hematopoietic cells, including pre-HSCs, arise through an intermediate hemogenic

or neonatal environments $[34,58,86]$. While IAHCs are also formed within lateral, dorsal and ventral endothelial layers, preferentially the ventral section had the autonomous capacity to generate HSCs with reconstitution potential [29]. This implies a dorso-ventral polarity of HSC generation and indicates a putative functional heterogeneity among IAHCs and, consequently, HE.

Astonishingly, the presence and functional activity of preHSCs have also been shown in the dorsal domain of the DA [87]. In accord with these findings, RNA-sequencing comparison of murine dorsal IAHCs and ventral IAHCs between E10 and E11 revealed only minor differences in the transcriptome [75]. However, the most dramatic transcriptional changes were observed mainly in the ventral IAHCs during the EHT process, as well as during formation and maturation of pre-HSCs [75]. This indicates an instructive role of anatomically distinct environments and, as a consequence, differential influences of signaling and cell-extrinsic factors on HE and IAHCs. Interestingly, the expression of hematopoietic-associated genes such as Runxl and Gata3 was described in murine $\mathrm{CD} 45^{-}$mesenchymal cells, which are located ventral to the DA [88-91]. This led to the hypothesis of a putative different and direct origin of HSCs and it has been speculated whether the sub-aortic mesenchymal floor endothelium (green), organized in intra-aortic hematopoietic clusters (IAHCs). This endothelial-to-hematopoietic transition (EHT) and HSC emergence is regulated and directly or indirectly influenced by signaling and cell-extrinsic factors from the microenvironment (e.g., vascular endothelial cells (light blue) and perivascular mesenchyme (purple))

of the AGM has an instructive role or directly gives rise to pre-HSCs. In vivo, lineage-tracing studies in the murine AGM indicated that this sub-aortic mesenchyme was not a direct progenitor of HSCs [39]. Some evidence suggests that the early, transient, lateral plate mesodermal-derived, mesenchymal population may contribute to the aortic floor endothelium [92], which, in turn, has the capacity for hematopoietic cell generation through an intermediate endothelium [39]. However, the role of the sub-aortic mesenchyme is still a matter of controversy in the field, which remains to be resolved [93].

The sub-aortic mesenchyme potentially provides an instructive microenvironment and signaling that supports EHT and, subsequently, HSC emergence. Elegant ex vivo studies of mouse E10.5 AGM region identified that interactions among three main signaling pathways favor HSC emergence in the ventral domain of the DA [87]. Overlapping gradients and asymmetric patterns of (1) urogenital ridge and ventral DA domain-derived stem cell factor (Scf), (2) sonic hedgehog (Shh) produced in the dorsal domain of the DA and (3) ventral Bmp4 inhibition through Noggin expression were found to be essential for the generation of HSCs in the ventral DA domain [87]. Similarly, different key signaling pathways were described to be indispensable 
for early mesodermal patterning and hemato-endothelial ontogenesis in animal models and that precise and spatiotemporal regulation of these pathways is critical. Early during zebrafish embryonic hematopoiesis, Bmp4 signaling was described to promote hematopoietic specification from mesoderm, mainly through induction of Wnt and, as a consequence, upregulation of caudal-related homeodomain (Cdx) TFs [94]. In mice, $\mathrm{Cdx} 1$ and $\mathrm{Cdx} 4$ are directly regulated by Wnt signaling $[95,96]$ and $\mathrm{Cdx}$ genes have been further described to control cell fate determination through Hox gene regulation [97]. These key signaling pathways are mostly conserved among vertebrates and have been exploited to direct in vitro hematopoietic differentiation. All of these pathways act as a dynamic, complex network of interacting signaling cascades to precisely mediate control of developmental stages and cell fate decisions.

Although there is remarkable evolutionary conservation among vertebrate genomes, considerable genetic differences between human and other vertebrate species have been observed, which contribute to crucial dissimilarities during embryonic hemato-endothelial development. These differences can be significant and might preclude the transfer of developmental concepts and regulation from model organisms to human developmental processes. Therefore, the use of human cells and especially differentiation of human PSCs emerged as a powerful tool to mimic and investigate human developmental processes and their regulation in vitro. However, many of the developmental concepts observed in model organisms, the cell-extrinsic and -intrinsic regulation of hemato-endothelial development, have been used to design successful hematopoietic differentiation protocols of human PSCs in vitro. The insights of these PSC-based hematopoietic differentiations can be used to validate the in vivo findings and complement and shape our knowledge about human hematopoietic ontogeny.

\section{Directed differentiation of PSCs towards hematopoietic cell types}

Directed differentiation is based on recapitulating and mimicking key aspects of embryonic hematopoiesis and the regulation of ontogenetic processes in vitro by instructive cellextrinsic factors [45, 98-105]. Directed hemato-endothelial differentiation of PSCs has been explored for decades [100, 106] and paved the way for the upcoming differentiation protocols. While many current directed differentiation protocols rely upon well-characterized serum-free medium components, there are still some less well-defined culture components such as factors derived from co-cultivation systems. In addition, it is difficult to quantify effects of cellextrinsic factors like cell-cell interactions on in vitro differentiation. This limits accurate control and reproducibility of the differentiation process and has thus far only produced a limited range of mature hematopoietic lineages and HPCs without long-term reconstitution potential. Thus, it is likely that directed hematopoietic differentiation rather resembles the first, transient, HSC-independent waves of embryonic hematopoiesis. Usage of more defined, serum-free media, defined morphogens, small molecules and culture conditions enables the production of hematopoietic cells and HE in a more defined and reproducible manner. However, the generation of PSC-derived, bona fide HSCs under in vitro conditions remains a significant challenge and is still a high priority in the fields of hematology and regenerative medicine. These restrictions are probably due to the lack of detailed understanding of human hemato-endothelial ontogeny and the limitations of recapitulating complex, dynamic, multifactorial developmental processes in vitro.

Although the clinical use of PSC-derived HSCs remains to be achieved, in vitro hematopoietic differentiations undoubtedly contributed to our current understanding of early human hematopoietic development. More importantly, early experiments provided compelling evidence that crucial stages of human ontogeny can be modeled in vitro. Several studies have convincingly demonstrated that primitive and definitive hematopoietic cells arise through specialized endothelial cells with hemogenic capacity $[45,55$, 107-111]. Mostly, directed differentiations generate different subtypes of mesodermal progenitors and cells with different hemogenic or vascular endothelial potential. Choi et al. identified hemogenic endothelial cells based on the immunophenotype $\mathrm{CD} 144^{+} / \mathrm{CD} 73^{-} / \mathrm{CD} 235 \mathrm{a}^{-} / \mathrm{CD} 43^{-}$. This HE gave rise to HPCs with an enhanced myeloid and erythroid lineage potential [45], but, more importantly, they neatly dissected hemato-endothelial specification from human PSCs and identified populations of cells with distinct endothelial and hematopoietic potential [45]. This indicates the simultaneous emergence of transient primitive and definitive hematopoietic programs in vitro and potential functional heterogeneity of the hemogenic capacity of the endothelial cells. Single cell transcriptional analysis of human iPSCderived $\mathrm{CD} 34^{+}$cells confirmed the functional heterogeneity. Transcriptional stages of $\mathrm{HE}$ cells $\left(\mathrm{CD} 34^{+} / \mathrm{CD} 43^{-} / \mathrm{CD} 90^{+} /\right.$ $\mathrm{CD}^{2} 3^{-} / \mathrm{CXCR}^{-}$) during the narrow window of the EHT process were dissected and were used to identify sub-populations with distinct hematopoietic lineage potential [112]. Based on these findings, it was hypothesized that the distinct hematopoietic lineage capacities are defined within the cell populations at the EHT stage, and therefore, before the complete loss of endothelial characteristics [112].

A different study proposed that distinct hematopoietic potential is already determined during mesodermal patterning. The erythroid surface marker CD235a was surprisingly found to be expressed on mesodermal, $\mathrm{KDR}^{+}$precursor cells, fated to the primitive hematopoietic lineages [105]. In 
contrast, the $\mathrm{KDR}^{+} / \mathrm{CD} 235 \mathrm{a}^{-}$mesodermal population could generate a broader spectrum of mature hematopoietic lineages, including T-lymphoid cells [105]. This fate determination was attributed to a dynamic interplay between the WNT signaling pathway and Activin-Nodal signaling [105] and has also been linked to the CDX-HOX pathway [113]. Similarly, modulation of the WNT and Activin-Nodal signaling pathways in mesodermal cells resulted in the upregulation of $C D X 4$ and, as a putative consequence, upregulation of HOXA3, HOXA5, HOXA7, HOXA9 and HOXA10 expression. Moreover, this modulation directed endothelial cells towards a SOX $17^{+}$aorta-like endothelial cell phenotype with hemogenic potential [114]. Although these studies demonstrated an enhanced hematopoietic potential, the definitive hematopoietic potential was measured based on the emergence of T-lymphoid cells. Generation of HSC-like cells with repopulating potential was not observed [105, 113, 114]. This suggests that the cells were either a progenitor of the transient EMP/LMPP hematopoiesis or indicated the requirement for additional, complementary regulatory factors or signaling to facilitate HSC function.

Consistent with the pivotal role of Notch signaling during endothelial development formation of the dorsal aorta and, as a consequence, HSC emergence [65-70], NOTCH-DLL1 signaling facilitates arterialization of human PSC-derived $\mathrm{HE}$ in vitro [64]. Interestingly, and in contrast to murine in vivo data [70], immobilized JAG1-Fc had only minor effects on hematopoiesis. Activation of NOTCH signaling through immobilized NOTCH-ligand DLL1-Fc in CD31 ${ }^{+}$ (PECAM1, an endothelial-specific marker) cells led to the upregulation of typical NOTCH-downstream genes (HES1) and expression of typical arterial-associated genes (e.g., DLL4, EFNB2, HEY2, SOX17, and CXCR4) in a transient, CD $144^{+} / \mathrm{CD} 73^{-} / \mathrm{CD} 43^{-} / \mathrm{DLL} 4^{+}$HE population. This HE had the capacity to undergo EHT and produce lymphoid, myeloid and erythroid cells in a NOTCH-dependent manner. In contrast, the non-arterialized HE population $\left(\mathrm{CD} 144^{+} /\right.$ $\mathrm{CD}^{-} 3^{-} \mathrm{CD} 3^{-} / \mathrm{DLL}^{-}$), showed mostly primitive hematopoietic potential. Although the arterialized HE was able to give rise to definitive lympho-myeloid hematopoietic cells, these cells were not engraftment-competent HSCs. Most strikingly, the arterialized HE had only the capacity to generate hematopoietic cells in co-culture with OP9-DLL4 cells, but not under defined, serum-free conditions. Thus, additional, unknown, stroma-cell derived factors were crucial for the EHT process, which activates or inhibits different signaling pathways.

The overall mode of action of signaling pathways is mostly similar. A cell-extrinsic signal is converted into a cellular response through intracellular signaling cascades and usually results in gene expression changes. TFs are often direct targets of signaling cascades, which directly alter the transcriptional response and, subsequently, downstream regulation of associated genes and transcriptional networks. Overexpression of these downstream TFs might bypass or provide shortcuts to complex cellular processes, cell-cell interactions and signaling cascades and might help to simplify demanding differentiation protocols and improve hemato-endothelial differentiation processes.

\section{Transcription factor-mediated enforced hematopoietic specification}

Alternative approaches have emerged to overcome the limitations of directed hematopoietic differentiation strategies by the generation of HE, hematopoietic cells, or even HSClike cells through ectopic expression of cell fate-determining TFs $[115,116]$. These TFs can either be overexpressed in (1) mature cell types for direct conversion into less committed intermediate precursors, or (2) PSCs for forward programming into specific lineages (Fig. 4 and Table 1). The identification of master regulators and, more importantly, interacting TF combinations and transcriptional networks is crucial for both strategies. Many TFs have been used in in vitro differentiation approaches based on their described key roles during vertebrate ontogeny in vivo.

Expression of the TF combination Gata2, Gfilb, and cFos (enhanced with Etv6) induced hematopoietic potential in murine fibroblasts. The transduced fibroblasts formed endothelial-like structures and produced hematopoietic cells in a dynamic process through a Tie $2^{+} \mathrm{CD} 144^{+} \mathrm{CD} 31^{+}$ endothelial intermediate [117]. Similarly, ectopic expression of these TFs (GATA2, GFIIB and FOS) was later used for initial induction of endothelial signature, followed by hematopoietic gene expression in human fibroblasts [118]. The hematopoietic cells arise through an endothelial intermediate and demonstrated an HSC-like immunophenotype of $\mathrm{CD}^{2} 4^{+} / \mathrm{CD} 49 \mathrm{f}^{+} / \mathrm{CD} 90^{+} / \mathrm{CD} 38^{-} / \mathrm{CD} 45 \mathrm{RA}^{-}$[118], similar to the phenotypic definition of human cord blood HSCs $[119,120]$. Most strikingly, these cells demonstrated moderate multi-lineage reconstitution potential in NSG mice up to 12 weeks post-transplantation [118]. While GATA2, GFI1B and FOS form a transcriptional complex that initiates expression of endothelial and hematopoietic genes, GATA2 was described to be the dominant transcription factor in this complex [114].

The conserved function of Gata2/GATA2 in mice and humans indicates the cooperative, dominant and instructive role of Gata2/GATA2 for induction of hemato-endothelial programs. In vivo, conditional knockout of Gata2 cis-regulatory elements in the murine AGM region resulted in diminished $\mathrm{Scl}$ and Runxl expression and abolished HSC generation from HE [121]. Gata 2 knockouts in $\mathrm{CD} 144^{+}$endothelial cells resulted in similar effects, along with lack of IAHC formation in the murine DA and HSC generation [122]. In vitro 


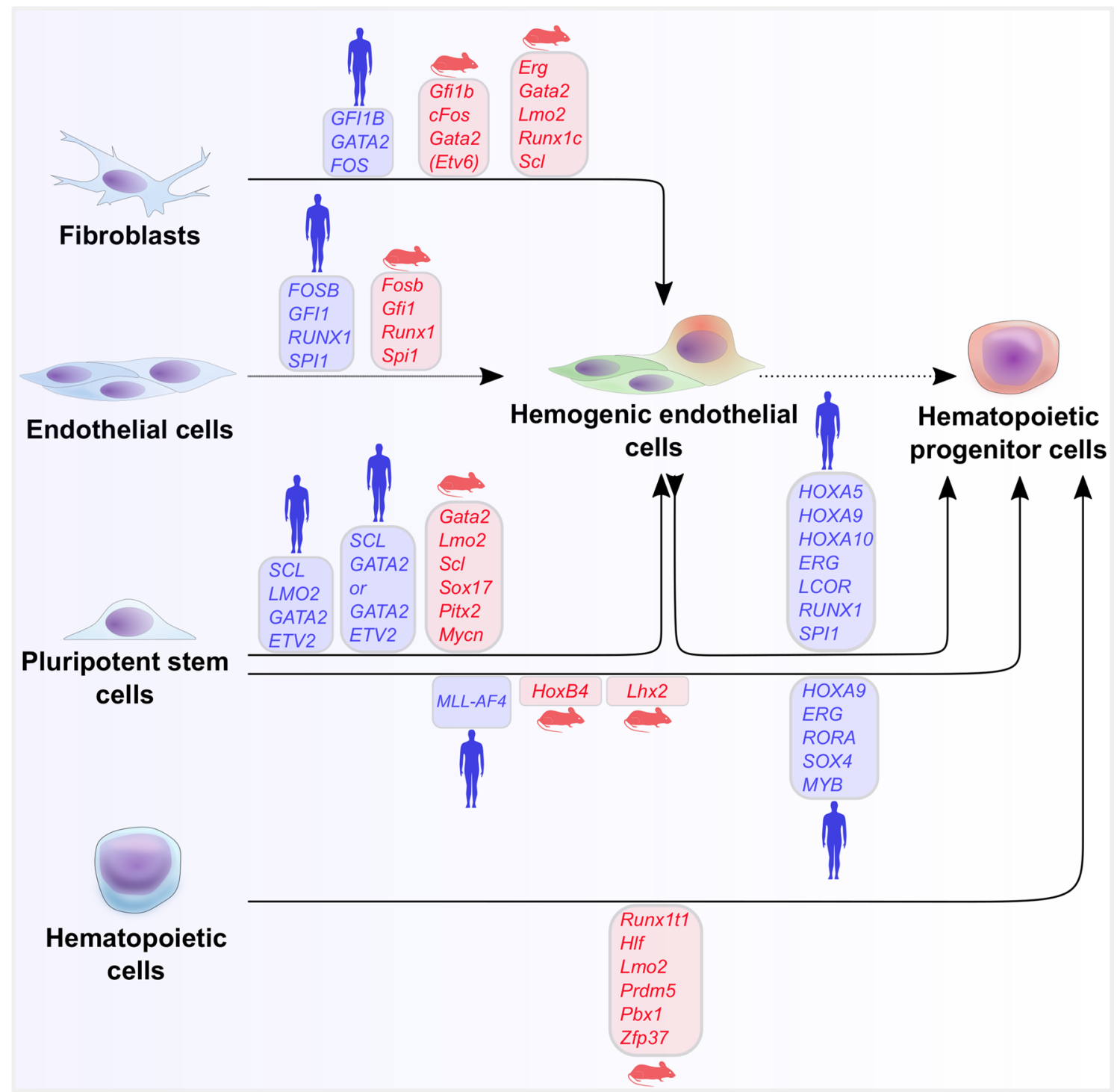

Fig. 4 Transcription factor-mediated hematopoietic differentiation strategies. Hematopoietic in vitro differentiation approaches based on the ectopic overexpression of transcription factors (TFs) in somatic cell sources, such as fibroblasts, mature non-hemogenic endothelial cells, lineage-committed hematopoietic cells or pluripotent stem cells,

differentiation of human embryonic stem cells (ESCs) suggested that GATA2 is crucial for the EHT process [123], likely due to transcriptional regulation of downstream targets. In mice, the Runx l cis-regulatory element (+23 Runx 1 enhancer) contains Gata and Ets motifs that regulate transcription [124]. Further, a transcriptional complex of Gata2, Fli1 and Scl was found to be recruited to the Runxl cisregulatory element, which placed the key hematopoietic TF Runx 1, directly downstream of these TFs [124]. Overexpression of some of these TFs (Erg, Gata2, Lmo2, Runx 1c, Scl) in murine fibroblasts induced hematopoietic specification and generation of multipotent HPCs through an intermediate such as embryonic stem cells (ESCs) or induced pluripotent stem cells (iPSCs). The used TFs/TF combinations are shown in boxes and color-coded in red for murine cell origin and blue for human cell origin

endothelial stage, with expression of typical endothelial markers (e.g., Cdh5, Tie2, Pecaml, and Vwf) [125]. These multipotent progenitors demonstrated an HSC-like immunophenotype, with robust erythroid, megakaryocytic and myeloid potential as well as lymphoid potential after loss of p53 function, but only short-term reconstitution ability of predominantly erythroid cells [125]. These approaches indicate that various transcriptional regulators, or even one specific TF, might be sufficient to activate and regulate similar gene regulatory networks to induce hemato-endothelial specification. However, the generation of bona fide HSCs was not achieved with these factors. This shortcoming might 
Table 1 TF-mediated hematopoietic differentiation approaches of murine and human cell origin. PSC-based approaches marked in light grey. Information modified and extended from Wahlster and Daley [157]

\begin{tabular}{|c|c|c|c|c|c|c|c|}
\hline Species & Approach & Cell Source & $\begin{array}{l}\text { Transcription } \\
\text { Factor }\end{array}$ & $\begin{array}{l}\text { Endothelial } \\
\text { intermediate }\end{array}$ & Lineages & Engraftment & Reference \\
\hline & $\begin{array}{c}\text { Direct } \\
\text { conversion }\end{array}$ & $\begin{array}{c}\text { primitive HPC } \\
\text { or ESC derived } \\
\text { HPC }\end{array}$ & HoxB4 & - & $\begin{array}{c}\text { Erythroid, Myeloid, } \\
\text { Lymphoid }\end{array}$ & Long-term & [144] \\
\hline & $\begin{array}{c}\text { Direct } \\
\text { conversion }\end{array}$ & Fibroblasts & $\begin{array}{c}\text { Gata2, Gfi1b, } \\
\text { cFos, Etv6 }\end{array}$ & Yes & $\begin{array}{l}\text { Myeloid, Erythroid, } \\
\text { Megakaryocytic }\end{array}$ & - & [117] \\
\hline & $\begin{array}{c}\text { Direct } \\
\text { conversion }\end{array}$ & Fibroblasts & $\begin{array}{c}\text { Erg, Gata2, } \\
\text { Lmo2, Runx1c, } \\
\text { Scl }\end{array}$ & Yes & $\begin{array}{l}\text { Myeloid, Erythroid, } \\
\text { Megakaryocytic }\end{array}$ & Short-term & [125] \\
\hline & $\begin{array}{c}\text { Direct } \\
\text { conversion }\end{array}$ & $\begin{array}{c}\text { Committed } \\
\text { hematopoietic } \\
\text { cells }\end{array}$ & $\begin{array}{c}\text { Runx1t1, Hlf, } \\
\text { Lmo2, Prdm5, } \\
\text { Pbx1, Zfp37 }\end{array}$ & - & $\begin{array}{l}\text { Myeloid, Erythroid, } \\
\text { Megakaryocytic, T- } \\
\text { cell, B-cell }\end{array}$ & Long-term & [126] \\
\hline & $\begin{array}{c}\text { Direct } \\
\text { conversion }\end{array}$ & $\begin{array}{l}\text { Endothelial } \\
\text { cells }\end{array}$ & $\begin{array}{l}\text { Fosb, Gfi1, } \\
\text { Runx1, Spi1 }\end{array}$ & Yes & $\begin{array}{l}\text { Myeloid, Erythroid, } \\
\text { Megakaryocytic, } \\
\text { Lymphoid }\end{array}$ & Long-term & [115] \\
\hline & $\begin{array}{c}\text { Direct } \\
\text { conversion }\end{array}$ & $\begin{array}{l}\text { Endothelial } \\
\text { cells }\end{array}$ & $\begin{array}{l}F O S B, G F I 1 \\
R U N X 1, S P I 1\end{array}$ & Yes & $\begin{array}{c}\text { Myeloid, Erythroid, } \\
\text { Megakaryocytic, } \\
\text { NK-cells, B-cell }\end{array}$ & Long-term & [127] \\
\hline & $\begin{array}{c}\text { Direct } \\
\text { conversion }\end{array}$ & Fibroblasts & $\begin{array}{l}\text { GFI1B, FOS, } \\
\text { GATA2 }\end{array}$ & Yes & Myeloid, Lymphoid & $\begin{array}{l}\text { Moderate } \\
\text { long-term }\end{array}$ & [118] \\
\hline & $\begin{array}{c}\text { Forward } \\
\text { programming }\end{array}$ & ESC & $\begin{array}{c}\text { Gata2, Lmo2, } \\
\text { Mycn, Pitx2, } \\
\text { Sox17, Scl }\end{array}$ & Yes & $\begin{array}{l}\text { Myeloid, Erythroid, } \\
\text { Megakaryocytic }\end{array}$ & - & [138] \\
\hline & $\begin{array}{c}\text { Forward } \\
\text { programming }\end{array}$ & ESC/iPSC & $\operatorname{Lh} \times 2$ & - & $\begin{array}{c}\text { Myeloid, Erythroid, } \\
\text { Megakaryocytic } \\
\text { B-cell }\end{array}$ & Long-term & [145] \\
\hline & $\begin{array}{l}\text { Forward } \\
\text { programming }\end{array}$ & PSC & $\begin{array}{l}\text { ETV2, GATA2 or } \\
\text { GATA2, SCL }\end{array}$ & Yes & $\begin{array}{l}\text { Myeloid, Erythroid, } \\
\text { Megakaryocytic }\end{array}$ & - & [137] \\
\hline & $\begin{array}{c}\text { Directed } \\
\text { differentiation } \\
\text { and forward } \\
\text { programming }\end{array}$ & 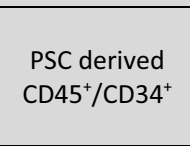 & $\begin{array}{c}\text { HOXA9, ERG, } \\
\text { RORA, SOX4, } \\
\text { MYB }\end{array}$ & Yes & $\begin{array}{c}\text { Erythroid, Myeloid, } \\
\text { Lymphoid }\end{array}$ & Short-term & [155] \\
\hline & $\begin{array}{c}\text { Directed } \\
\text { differentiation } \\
\text { and forward } \\
\text { programming }\end{array}$ & $\begin{array}{c}\text { iPSC-derived } \\
\mathrm{HE}\end{array}$ & $\begin{array}{c}\text { ERG, HOXA5, } \\
\text { HOXA9, HOXA10, } \\
\text { LCOR, RUNX1, } \\
\text { SPI1 }\end{array}$ & Yes & $\begin{array}{l}\text { Myeloid, Erythroid, } \\
\text { Megakaryocytic, T- } \\
\text { cell, B-cell }\end{array}$ & $\begin{array}{l}\text { Long-term } \\
\text { after } \\
\text { intrafemoral } \\
\text { injection }\end{array}$ & [116] \\
\hline & $\begin{array}{c}\text { Directed } \\
\text { differentiation } \\
\text { and forward } \\
\text { programming }\end{array}$ & $\begin{array}{l}\text { iPSC-derived } \\
\text { hematopoietic } \\
\text { cells }\end{array}$ & MLL-AF4 & - & $\begin{array}{l}\text { Myeloid, Erythroid, } \\
\text { Megakaryocytic, T- } \\
\text { cell, B-cell }\end{array}$ & $\begin{array}{l}\text { Long-term, } \\
\text { prone to } \\
\text { transformation }\end{array}$ & [140] \\
\hline & $\begin{array}{c}\text { Forward } \\
\text { programming }\end{array}$ & PSC & ETS1 & Yes & $\begin{array}{l}\text { Myeloid, Erythroid, } \\
\text { Megakaryocytic, T- } \\
\text { cell, B-cell }\end{array}$ & - & [139] \\
\hline & $\begin{array}{c}\text { Forward } \\
\text { programming }\end{array}$ & iPSC & $\begin{array}{l}\text { SCL, LMO2, } \\
\text { GATA2, ETV2 }\end{array}$ & Yes & $\begin{array}{l}\text { Myeloid, Erythroid, } \\
\text { Megakaryocytic, } \\
\text { NK-cell }\end{array}$ & - & [135] \\
\hline
\end{tabular}

be attributed to an incomplete understanding of transcriptional regulation, limitations of the in vitro culture or the requirement for an instructive and supportive niche.

A screening approach identified 6 out of 36 HSC-associated transcriptional regulators to induce re-specification of committed, murine lymphoid and myeloid progenitor cells into HSCs without an endothelial intermediate [126]. Transient overexpression of these six transcriptional regulators Run1t1, Hlf, Lmo2, Prdm5, Pbxl and Zfp37 was sufficient to confer HSC functionality and, most strikingly, long-term, multi-lineage reconstitution potential in primary and secondary recipients [126]. Interestingly, transient ectopic expression of these factors was sufficient to sustain the HSC functionality in vivo and stably activate gene regulatory networks that govern HSC function and identity [126].

Taking advantage of the close ontological relation between endothelial cells and hematopoietic cells, enforced expression of the four TFs FOSB, GFII, RUNXI and SPII 
reprogrammed human, non-hemogenic mature and fetal endothelial cells into self-renewing, engraftment-competent multipotent progenitors, although, with insufficient $\mathrm{T}$ cell potential [127]. An immortalized endothelial cell line that was previously described to support HSC expansion, likely through AKT-regulated factors, was shown to contribute to an instructive niche, which is crucial for the formation of the HE, the EHT process and the generation of multipotent progenitors [128]. More recently, overexpression of the same TFs (Fosb, Gfil, Runxl and Spil) and these vascularniche-derived factors were sufficient to fully reprogram adult murine endothelial cells into HSCs with proper functionality [115]. While these approaches were mostly initiated from mature somatic cells, TF-mediated differentiation was also used to direct hemato-endothelial specification from PSCs.

In vertebrates, the ETS-family (E26 transformation specific) TFs contain approximately 30 members (e.g., FLI1, ERG, ETV2, ETV6, SPI1, and ETS1) and have been described as key TFs that regulate early vasculogenesis and hematopoietic development [129]. The ETS-family TF ETV2 (ETS variant 2) is expressed early during mesodermal formation in cells with endothelial and hematopoietic potential $[130,131]$ and was shown to induce expression of several endothelial- and hematopoietic-associated downstream targets [132], indicating that ETV2 governs activation of hemato-endothelial transcriptional networks. Knockout studies in mice further supported this crucial role of Etv2 during endothelial development. Etv2 ablation resulted in significantly diminished Kdr expression and early embryonic lethality due to a complete lack of endothelial and hematopoietic specification [132, 133]. In vitro differentiation experiments validated the crucial and instructive role of ETV2. Ectopic expression of ETV2 induced expression of endothelial-associated genes (e.g., FLII, ERG, CDH5, $K D R$, and $P E C A M 1$ ) and, more importantly, was sufficient to directly convert human fibroblasts into functional endothelial cells [134]. Inducible overexpression of ETV2 in human iPSC-derived, mesodermal-primed cells resulted in an almost pure population of cells with a vascular endothelial immunophenotype $\left(\mathrm{CD} 144^{+} / \mathrm{CD} 73^{+}\right)$[135]. Similarly, transient expression of exogenous ETV2 by modified and stabilized mRNA efficiently generated functional endothelial cells with the ability to form perfused vascular networks in vivo [136]. However, overexpression of ETV2 alone was not described to robustly induce hemogenic potential. A gain-of-function screen of hemato-endothelial-associated TFs in human PSCs revealed synergistic effects of ETV2/ GATA2 or SCL/GATA2 on hematopoietic specification [137]. Both TF combinations induced a hemato-endothelial program and generated hematopoietic cells through an intermediate endothelial state with distinct hematopoietic lineage potential [137]. Using a forward programming approach of human iPSCs, controlled overexpression of the
TF combination $S C L / L M O 2 / G A T A 2 / E T V 2$ robustly induced hemato-endothelial specification with an almost pure population of cells with an HE-like phenotype and, subsequently, multi-lineage HPCs [135]. However, both attempts [135, 137] demonstrated restricted lineage potential (erythroid, myeloid, megakaryocytic) with lymphoid limitations and, most strikingly, without significant engraftment and reconstitution potential. Furthermore, collective overexpression of the six TFs Gata2, Lmo2, Scl, Sox17, Pitx2 and Mycn directly converted murine PSCs to hemato-endothelial cells, smooth muscle cells and hematopoietic cells [138]. Downregulation of these TFs resulted in the generation of multilineage hematopoietic cells through an endothelial intermediate, which were, however, restricted to erythroid, myeloid and megakaryocytic lineages [138].

In concordance with the crucial role of the arterial identity of definitive HE in vivo [59-62, 65, 67, 69, 71, 73] and the impact of arterialized HE through Notch signaling in vitro [64], overexpression of ETS1 or modulation of the MAPK/ERK signaling pathway induced HE with arterial characteristics and enhanced lineage potential [139]. Upon ectopic ETS1 expression at the mesodermal stage, the formation of $\mathrm{KDR}^{+} / \mathrm{CD} 144^{+}$endothelial cells was increased. In this endothelial population, arterial-associated genes were upregulated, including CXCR4, EFNB2, SOX7, SOX17, SOX18 and genes of the NOTCH signaling pathway such as DLL4, NOTCHI, NOTCH4, and HEYl. The venous-specific gene $N R 2 F 2$ was not upregulated upon enforced ETS1 expression, implying an arterial-specific effect of ETS1, and suggested that HE, similar to the vascular endothelium, can acquire an arterial identity. The resulting, arterialized $\mathrm{CD} 144^{+} / \mathrm{CD} 43^{-} / \mathrm{CD} 73^{-} / \mathrm{DLL} 4^{+} \mathrm{HE}$ generated an increased number of $\mathrm{CD} 45^{+} / \mathrm{CD} 235^{-} / \mathrm{CD} 41 \mathrm{a}^{-}$HPCs with erythro-myeloid and lymphoid potential. In line with a similar approach [64], the effect of the ETS1-mediated arterialization and enhanced hematopoietic potential was primarily mediated through upregulation of the NOTCH-ligand DLL4 and activation of NOTCH-mediated signaling [139]. However, both studies $[64,139]$ failed to achieve short- or longterm engraftment and led to speculation about the necessity for additional arterialization and $\mathrm{NOTCH}$-independent mechanisms that regulate HSC specification, such as the HOXA gene cluster.

A variety of TFs act as master regulators and govern endothelial as well as hematopoietic ontogenesis. Transient overexpression of the MLL (mixed lineage, myeloid lymphoid leukemia)-fusion protein MLL-AF4 reprogrammed human iPSC-derived hematopoietic cells into highly engraftment-competent HSCs [140]. Although these HSCs demonstrated high levels of engraftment and reconstituted both lymphoid and myeloid lineages, the MLL-AF4-induced iPSC-derived HSCs were prone to leukemic transformation after transplantation [140]. In vivo, MLL is a positive 
regulator of Hox genes through direct binding to promoter sequences [141, 142] (as discussed below). Especially HOXB4 was shown to enhance self-renewal, hematopoietic capacity and, most strikingly, engraftment and repopulating potential in mice [143]. Overexpression of HoxB4 in murine yolk sac hematopoietic progenitors or murine ESCs enabled the generation of HSC-like cells, which were able to engraft and reconstitute lympho-myeloid hematopoiesis in irradiated murine recipients [144]. Similarly, enforced expression of the LIM-homeobox TF Lhx 2 conferred long-term reconstitution potential to murine ESCs and iPSCs in primary and secondary recipient mice, however, without T-lymphoid contribution [145]. In contrast to murine ESCs/iPSCs, the repopulating capacity of human ESC/iPSC-derived hematopoietic cells was not positively affected by overexpression of HOXB4 [146], indicating considerable differences between transcriptional regulation of human and murine hematopoietic development. Nevertheless, these studies convincingly demonstrated that overexpression of a single TF could significantly influence PSC differentiation. However, these studies mainly focused on ESC/iPSC-derived HSCs. The direct, intermediate precursor, the HE, was neglected. Later, ectopic $\mathrm{HOXB} 4$ expression during the $\mathrm{KDR}^{+}$-stage of differentiated ESCs was associated with the promotion of HE formation [147]. The acquisition of the HE cell fate was linked to a shift of the transcriptional signature and upregulation of crucial genes and TFs for endothelial specification and hematopoiesis, such as Cdh5, Cd34, Scl, Gata2, Erg, Fli1, Lyll and Lmo2 [147]. Combinatorial expression of some of these TFs has been used to direct hemato-endothelial differentiation in several approaches.

The HOX genes are located in different clusters, HOXA$H O X D$, characterized by the common homeobox DNA-binding domain [148]. The specificity and selectivity of HOX TFs are relatively low and mostly mediated and increased through co-factor binding [149]. Concomitant with the low specificity of HOX TFs, the functionality of HOX TFs during embryogenesis is diverse. Members of the HOX gene cluster are required for maintenance and self-renewal of hematopoietic progenitors or HSCs [143, 150]. Expression of the HOX gene clusters is controlled by upstream regulators, such as the MLL [142], members of the CDX TFs (CDX1, CDX2, and CDX4) [97] or the retinoic acid signaling pathway [151]. Dysregulation of the HOX TFs was associated with different hematopoietic malignancies [148], reflecting the crucial role and complexity of regulation of the HOX gene cluster. Hox knockout studies validated the crucial role of their function during hematopoietic ontogeny and HSC maintenance. Especially HoxA9 knockouts demonstrated severely impaired HSC self-renewal and proliferation [152] and significantly decreased the reconstitution capacities of fetal liver HSCs in mice [153]. It was hypothesized that the medial HOXA genes have a key role during hematopoietic differentiation and that the lack of HOXA expression might be a significant barrier that prevents the in vitro generation of human PSC-derived bona fide HSCs [151]. Several gain-of-function studies validated the crucial role of HOX genes. Ectopic expression of HOXA9 alone was insufficient to confer self-renewal or long-term repopulation potential to human ESC-derived HPCs [154]. A different approach identified crucial TF combinations to overcome erythro-myeloid restriction and confer enhanced, HSC-like properties to human PSC-derived hematopoietic cells [155]. An extensive in vitro screen identified the TF combination HOXA9, ERG and RORA to be sufficient to respecify the myeloid restricted, $\mathrm{PSC}$-derived $\mathrm{CD} 34^{+} / \mathrm{CD} 38^{-}$HPCs to a proliferative, self-renewing stage with an enhanced erythroid and lymphoid lineage potential. The addition of SOX4 and $M Y B$ overexpression enabled short-term myelo-erythroid engraftment. Although ectopic expression of these TFs enhanced the stem cell properties of the formerly restricted HPCs, long-term engraftment and multi-lineage reconstitution were not achieved. Interestingly, it was hypothesized that the definitive hematopoietic program and HSC generation in vitro might be actively repressed through epigenetic silencing [156]. A screening experiment for DNA- and histone-modifying factors that repress the definitive hematopoietic program and multipotency identified EZH1 as a crucial repressor. EZH1 is a component of the Polycomb repressive complex 2 and mediates target-site-specific epigenetic silencing through histone methylation. Strikingly, EZH1 was found to directly bind promoters of HSC-associated genes, such as HLF, HOPX, MEIS1, PRDM16, LMO2, ETS1, HESI, RUNXI and HOX clusters. EZHI knockdown increased gene expression of arterial- and HSC-associated genes such as NOTCH, HES1, HEY1, SOX17, RUNX1T1 and FOXC2, and elicited robust $\mathrm{T}$ and $\mathrm{B}$ cell potential of the previously described [155] differentiation protocol [156]. In mice, Ezh1 deficiency or haploinsufficiency increased the HSC frequencies compared to wild type animals, and stimulated the precocious generation of bona fide HSCs during in vivo ontogenesis, presumably through enhanced accessibility of key HSC TF-binding sites [156]. A combined approach that applied directed differentiation and TF-mediated specification was shown to confer HSC-like functionality to human PSC-derived HE [116]. A library of 26 fetal liver HSC-enriched TFs was used to screen for a factor combination to confer HSC functionality to a PSC-derived HE population. The $\mathrm{CD} 34^{+} / \mathrm{KDR}^{+} / \mathrm{CD} 43^{-} / \mathrm{CD} 235 \mathrm{a}^{-}$endothelium was transduced with this library and $24 \mathrm{~h}$ later intrafemorally injected into sublethally irradiated mice. Multi-lineage engraftment of myeloid, erythroid and lymphoid lineages was observed 12 weeks post-transplantation. Enrichment of the seven TFs HOXA5, HOXA9, HOXA10, ERG, LCOR, $R U N X I$ and SPII was consistently detected, indicating that these factors enabled self-renewal, engraftment and 
multi-lineage reconstitution potential [116]. Engraftment of secondary recipient mice validated the self-renewal capacity that was conferred by the 7 TFs. However, compared to cord blood CD34 ${ }^{+}$-transplanted mice, the robustness of the multilineage engraftment (9/76 mice) was lower and also the full recapitulation of the reconstituted lineages was biased [116]. This approach suggested that the generation of PSC-derived bona fide $\mathrm{HSC}$ is becoming more feasible. However, TFbased strategies for the in vitro generation of PSC-derived, bona fide HSCs for clinical use remains a high priority that has yet to be realized.

\section{Conclusion and perspectives}

In summary, recent work clearly illustrated remarkable progress in the conversion of (i) PSCs and somatic cell types into $\mathrm{HE}$ as an important intermediate towards the development of HSCs. As the generation of fully engraftment-competent HSCs with multi-lineage developmental capacity in the sense of definitive hematopoiesis is cumbersome and a goal that remains to be achieved, we can further learn from the natural development of HE, subsequent HSCs and their neighboring niche components to identify crucial extrinsic and intrinsic regulating factors. Here, insights in single cell transcriptomics, including scRNAseq, will continue to identify critical developmental steps and cell types and will shed further light on the underlying transcriptional network, including instructive TFs and their expression levels. Moreover, spatial transcriptomics may further unravel the role of neighboring cells, including the role of crucial components of the microenvironment, necessary for conferring HSC identity, functionality, maintenance and expansion.

Correct dosing and timing of expression of transcription factors and extrinsic niche factors will be important to mimic and recapitulate the complex developmental process in vitro, for which state-of-the-art vector systems for regulated, timed and dosed expression will be needed. Here, especially transient vector expression systems will be interesting to explore the possibilities to mimic the waves and levels of hematopoietic factor expression. In addition, transient expression patterns will be desirable to avoid permanent expression of potentially oncogenic TFs and growth factors, and thus reduce (pre)malignant transformation of hematopoietic progenitors. For example, controlled delivery of the necessary TFs at the optimal time window during differentiation could be a further improvement of direct conversion protocols and forward programming strategies.

Although enforced overexpression of TFs has been used to increase hematopoietic potential and functionality of in vitro-derived hematopoietic cells, clinical translation of TF-based approaches remains to be achieved due to insufficient functionality and quantity of the cell product. The knowledge gained from TF-based strategies is helping to elucidate the key regulatory pathways whose modulation is necessary for directed differentiation towards HSCs. Future strategies will exploit this information to generate bona fide HSCs without the potential dangers of transformation due to TF overexpression.

Looking into the future, while we are getting closer to being able to generate high-quality transplantable hematopoietic cells, it will be necessary to establish the framework for GLP-/GMP (good laboratory practice/good manufacturing practice)-compliant production, including the generation of standard operating procedures (SOPs) and the inclusion of fully traceable and animal-free reagents in a GLP-compatible lab environment, to create a perspective for upscaling as needed in future clinical trials. For example, GMP-compliant cell modification and TF delivery strategies will have to be developed.

Moreover, thinking in the context of next-generation hematopoietic cell transplants, the horizon of combined gene and cell therapeutics should be considered. The use of precision medicine approaches, e.g., clinically used viral vectors and next-generation genome editing tools, will allow the tailored repair of genetic defects of autologous transplants as well as the generation of allogeneic "off-the-shelf" transplants, which may be transplantable to a broad spectrum of patients and diseases, especially in cases in which no suitable HSC donor is available. In addition to HSCs, also PSC-derived T, NK and NKT cells are interesting tools for tailored immunotherapeutics. HLA borders represent an important bottleneck to allogeneic cell replacement strategies. Here, the use of biobanking of iPSC for frequently used HLA subtypes or other "off-theshelf" implementation strategies could be helpful.

Taken together, the increasing insights in PSC-derived hematopoiesis as well as the HE may allow the tailored generation of hematopoietic cells for disease modeling, cell therapy and potentially even next-generation transplants.

Author contributions LL wrote the manuscript and designed the figures. MM and AS provided conceptual advice and support as well as edited/revised the manuscript.

Funding Open Access funding enabled and organized by Projekt DEAL. This work was supported by grants from DFG (REBIRTH Cluster of Excellence (EXC62/2) and SFB738), the REBIRTH Center for Translational Regenerative Medicine through the State of Lower Saxony (MWK: ZN3440) and received funding from the European Research Council (ERC) under Grant agreement No. 819531.

\section{Compliance with ethical standards}

Conflict of interest The authors declare no conflict of interest. 
Open Access This article is licensed under a Creative Commons Attribution 4.0 International License, which permits use, sharing, adaptation, distribution and reproduction in any medium or format, as long as you give appropriate credit to the original author(s) and the source, provide a link to the Creative Commons licence, and indicate if changes were made. The images or other third party material in this article are included in the article's Creative Commons licence, unless indicated otherwise in a credit line to the material. If material is not included in the article's Creative Commons licence and your intended use is not permitted by statutory regulation or exceeds the permitted use, you will need to obtain permission directly from the copyright holder. To view a copy of this licence, visit http://creativecommons.org/licenses/by/4.0/.

\section{References}

1. Copelan EA (2006) Hematopoietic stem-cell transplantation. N Engl J Med 354:1813-1826. https://doi.org/10.1056/NEJMr a052638

2. Appelbaum FR (2007) Hematopoietic-cell transplantation at 50. N Engl J Med 357:1472-1475. https://doi.org/10.1056/NEJMp 078166

3. Wilkinson AC, Ishida R, Kikuchi M et al (2019) Long-term ex vivo haematopoietic-stem-cell expansion allows nonconditioned transplantation. Nature. https://doi.org/10.1038/s4158 6-019-1244-x

4. Takahashi K, Tanabe K, Ohnuki M et al (2007) Induction of pluripotent stem cells from adult human fibroblasts by defined factors. Cell 131:861-872. https://doi.org/10.1016/j. cell.2007.11.019

5. Takahashi K, Yamanaka S (2006) Induction of pluripotent stem cells from mouse embryonic and adult fibroblast cultures by defined factors. Cell 126:663-676. https://doi.org/10.1016/J. CELL.2006.07.024

6. Blau HM, Daley GQ (2019) Stem cells in the treatment of disease. N Engl J Med 380:1748-1760. https://doi.org/10.1056/ NEJMra1716145

7. Suzuki N, Yamazaki S, Yamaguchi T et al (2013) Generation of engraftable hematopoietic stem cells from induced pluripotent stem cells by way of teratoma formation. Mol Ther 21:14241431. https://doi.org/10.1038/MT.2013.71

8. Amabile G, Welner RS, Nombela-Arrieta C et al (2013) In vivo generation of transplantable human hematopoietic cells from induced pluripotent stem cells. Blood 121:1255-1264. https:// doi.org/10.1182/blood-2012-06-434407

9. Coultas L, Chawengsaksophak K, Rossant J (2005) Endothelial cells and VEGF in vascular development. Nature 438:937-945. https://doi.org/10.1038/nature04479

10. Palis J, Robertson S, Kennedy M et al (1999) Development of erythroid and myeloid progenitors in the yolk sac and embryo proper of the mouse. Development 126:5073-5084

11. Rowe RG, Mandelbaum J, Zon LI, Daley GQ (2016) Engineering hematopoietic stem cells: lessons from development. Cell Stem Cell 18:707-720. https://doi.org/10.1016/j.stem.2016.05.016

12. Tober J, Koniski A, McGrath KE et al (2007) The megakaryocyte lineage originates from hemangioblast precursors and is an integral component both of primitive and of definitive hematopoiesis. Blood 109:1433-1441. https://doi.org/10.1182/blood -2006-06-031898

13. Bertrand JY, Jalil A, Klaine M et al (2005) Three pathways to mature macrophages in the early mouse yolk sac. Blood 106:3004-3011. https://doi.org/10.1182/BLOOD-2005-02-0461

14. Lux CT, Yoshimoto M, McGrath K et al (2008) All primitive and definitive hematopoietic progenitor cells emerging before
E10 in the mouse embryo are products of the yolk sac. Blood 111:3435-3438. https://doi.org/10.1182/blood-2007-08-10708 6

15. Yamane T (2018) Mouse Yolk Sac Hematopoiesis. Front cell Dev Biol 6:80. https://doi.org/10.3389/fcell.2018.00080

16. Yoshimoto M, Montecino-Rodriguez E, Ferkowicz MJ et al (2011) Embryonic day 9 yolk sac and intra-embryonic hemogenic endothelium independently generate a B-1 and marginal zone progenitor lacking B-2 potential. Proc Natl Acad Sci 108:1468-1473. https://doi.org/10.1073/pnas.1015841108

17. Yoshimoto M, Porayette P, Glosson NL et al (2012) Autonomous murine $\mathrm{T}$-cell progenitor production in the extra-embryonic yolk sac before HSC emergence. Blood 119:5706-5714 https://doi.org/10.1182/BLOOD-2011-12-397489

18. Frame JM, McGrath KE (2013) Erythro-myeloid progenitors: "Definitive" hematopoiesis in the conceptus prior to the emergence of hematopoietic stem cells. Blood Cells, Mol Dis 51:220-225. https://doi.org/10.1016/J.BCMD.2013.09.006

19. Lacaud G, Kouskoff V (2017) Hemangioblast, hemogenic endothelium, and primitive versus definitive hematopoiesis. Exp Hematol 49:19-24. https://doi.org/10.1016/j.exphe m.2016.12.009

20. Yoder MC, Hiatt K, Dutt P et al (1997) Characterization of definitive lymphohematopoietic stem cells in the day 9 murine yolk sac. Immunity 7:335-344. https://doi.org/10.1016/S1074 -7613(00)80355-6

21. Yoder MC, Hiatt K, Mukherjee P (1997) In vivo repopulating hematopoietic stem cells are present in the murine yolk sac at day 9.0 postcoitus. Proc Natl Acad Sci USA 94:6776-6780. https://doi.org/10.1073/PNAS.94.13.6776

22. Tavian M, Robin C, Coulombel L, Péault B (2001) The human embryo, but not its yolk sac, generates lympho-myeloid stem cells: Mapping multipotent hematopoietic cell fate in intraembryonic mesoderm. Immunity 15:487-495. https://doi. org/10.1016/S1074-7613(01)00193-5

23. Julien E, El Omar R, Tavian M (2016) Origin of the hematopoietic system in the human embryo. FEBS Lett 590:3987-4001

24. Müller AM, Medvinsky A, Strouboulis J et al (1994) Development of hematopoietic stem cell activity in the mouse embryo. Immunity 1:291-301. https://doi.org/10.1016/10747613(94)90081-7

25. Ivanovs A, Rybtsov S, Welch L et al (2011) Highly potent human hematopoietic stem cells first emerge in the intraembryonic aorta-gonad-mesonephros region. J Exp Med 208:24172427. https://doi.org/10.1084/jem.20111688

26. Medvinsky A, Dzierzak E (1996) Definitive hematopoiesis is autonomously initiated by the AGM region. Cell 86:897-906. https://doi.org/10.1016/S0092-8674(00)80165-8

27. Godin IE, Garcia-Porrero JA, Coutinho A et al (1993) Paraaortic splanchnopleura from early mouse embryos contains B1a cell progenitors. Nature 364:67-70. https://doi. org/10.1038/364067a0

28. Medvinsky AL, Samoylina NL, Müller AM, Dzierzak EA (1993) An early pre-liver intraembryonic source of CFU-S in the developing mouse. Nature 364:64-67. https://doi.org/10.1038/36406 $4 \mathrm{a} 0$

29. Taoudi S, Medvinsky A (2007) Functional identification of the hematopoietic stem cell niche in the ventral domain of the embryonic dorsal aorta. Proc Natl Acad Sci USA 104:93999403. https://doi.org/10.1073/pnas.0700984104

30. Garcia-Porrero JA, Godin IE, Dieterlen-Lièvre F, DieterlenLièvre F (1995) Potential intraembryonic hemogenic sites at pre-liver stages in the mouse. Anat Embryol (Berl) 192:425-435. https://doi.org/10.1007/BF00240375 
31. Tavian M, Hallais MF, Péault B (1999) Emergence of intraembryonic hematopoietic precursors in the pre-liver human embryo. Development 126:793-803

32. Gekas C, Dieterlen-Lièvre F, Orkin SH, Mikkola HKA (2005) The placenta is a niche for hematopoietic stem cells. Dev Cell 8:365-375. https://doi.org/10.1016/J.DEVCEL.2004.12.016

33. Kumaravelu P, Hook L, Morrison AM et al (2002) Quantitative developmental anatomy of definitive haematopoietic stem cells/ long-term repopulating units (HSC/RUs): role of the aortagonad-mesonephros (AGM) region and the yolk sac in colonisation of the mouse embryonic liver. Development 129:4891-4899

34. Rybtsov S, Sobiesiak M, Taoudi S et al (2011) Hierarchical organization and early hematopoietic specification of the developing HSC lineage in the AGM region. J Exp Med 208:13051315. https://doi.org/10.1084/jem.20102419

35. Ema H, Nakauchi H (2000) Expansion of hematopoietic stem cells in the developing liver of a mouse embryo. Blood 95:22842288. https://doi.org/10.1182/blood.V95.7.2284

36. Gao S, Liu F (2018) Fetal liver: an ideal niche for hematopoietic stem cell expansion. Sci China Life Sci 61:885-892. https://doi. org/10.1007/s11427-018-9313-4

37. Sabin FR (1917) Preliminary note on the differentiation of angioblasts and the method by which they produce blood-vessels. Anat Rec 13:5-7

38. Fraser ST, Ogawa M, Yu RT et al (2002) Definitive hematopoietic commitment within the embryonic vascular endothelialcadherin+ population. Exp Hematol 30:1070-1078. https://doi. org/10.1016/S0301-472X(02)00887-1

39. Zovein AC, Hofmann JJ, Lynch M et al (2008) Fate tracing reveals the endothelial origin of hematopoietic stem cells. Cell Stem Cell 3:625-636. https://doi.org/10.1016/j.stem.2008.09.018

40. Boisset J-C, van Cappellen W, Andrieu-Soler C et al (2010) In vivo imaging of haematopoietic cells emerging from the mouse aortic endothelium. Nature 464:116-120. https://doi. org $/ 10.1038 /$ nature 08764

41. Kissa K, Herbomel P (2010) Blood stem cells emerge from aortic endothelium by a novel type of cell transition. Nature 464:112115. https://doi.org/10.1038/nature08761

42. Nadin BM, Goodell MA, Hirschi KK (2003) Phenotype and hematopoietic potential of side population cells throughout embryonic development. Blood 102:2436-2443. https://doi. org/10.1182/blood-2003-01-0118

43. Nishikawa SI, Nishikawa SI, Hirashima M et al (1998) Progressive lineage analysis by cell sorting and culture identifies FLK1+VE-cadherin + cells at a diverging point of endothelial and hemopoietic lineages. Development 125:1747-1757. https ://doi.org/10.1111/ijpo.259

44. Rafii S, Kloss CC, Butler JM et al (2013) Human ESC-derived hemogenic endothelial cells undergo distinct waves of endothelial to hematopoietic transition. Blood 121:770-780. https://doi. org/10.1182/blood-2012-07-444208

45. Choi KD, Vodyanik MA, Togarrati PP et al (2012) Identification of the hemogenic endothelial progenitor and its direct precursor in human pluripotent stem cell differentiation cultures. Cell Rep 2:553-567. https://doi.org/10.1016/j.celrep.2012.08.002

46. Vodyanik MA, Thomson JA, Slukvin II (2006) Leukosialin (CD43) defines hematopoietic progenitors in human embryonic stem cell differentiation cultures. Blood 108:2095-2105. https:// doi.org/10.1182/blood-2006-02-003327

47. Eilken HM, Nishikawa S-I, Schroeder T (2009) Continuous single-cell imaging of blood generation from haemogenic endothelium. Nature 457:896-900. https://doi.org/10.1038/nature07760

48. Ivanovs A, Rybtsov S, Anderson RA et al (2014) Identification of the niche and phenotype of the first human hematopoietic stem cells. Stem Cell Reports 2:449-456. https://doi.org/10.1016/j. stemcr.2014.02.004
49. Tavian M, Coulombel L, Luton D et al (1996) Aorta-associated CD34+ hematopoietic cells in the early human embryo. Blood 87:67-72

50. Li W, Ferkowicz MJ, Johnson SA et al (2005) Endothelial cells in the early murine yolk sac give rise to CD41-expressing hematopoietic cells. Stem Cells Dev 14:44-54. https://doi. org/10.1089/scd.2005.14.44

51. Garcia-Porrero JA, Manaia A, Jimeno J et al (1998) Antigenic profiles of endothelial and hemopoietic lineages in murine intraembryonic hemogenic sites. Dev Comp Immunol 22:303319. https://doi.org/10.1016/S0145-305X(98)00006-8

52. Jaffredo T, Bollerot K, Sugiyama D et al (2005) Tracing the hemangioblast during embryogenesis: developmental relationships between endothelial and hematopoietic cells. Int J Dev Biol 49:269-277. https://doi.org/10.1387/ijdb.041948tj

53. Ottersbach K, Dzierzak E (2005) The murine placenta contains hematopoietic stem cells within the vascular labyrinth region. Dev Cell 8:377-387. https://doi.org/10.1016/J.DEVCE L.2005.02.001

54. Li Z, Lan Y, He W et al (2012) Mouse embryonic head as a site for hematopoietic stem cell development. Cell Stem Cell 11:663-675. https://doi.org/10.1016/j.stem.2012.07.004

55. Stefanska M, Batta K, Patel R et al (2017) Primitive erythrocytes are generated from hemogenic endothelial cells. Sci Rep 7:1-10. https://doi.org/10.1038/s41598-017-06627-9

56. Frame JM, Fegan KH, Conway SJ et al (2016) Definitive hematopoiesis in the yolk sac emerges from Wnt-responsive hemogenic endothelium independently of circulation and arterial identity HHS Public Access Graphical Abstract. Stem Cells 34:431-444. https://doi.org/10.1002/stem.2213

57. Goldie LC, Lucitti JL, Dickinson ME, Hirschi KK (2008) Cell signaling directing the formation and function of hemogenic endothelium during murine embryogenesis. Blood 112:31943204. https://doi.org/10.1182/blood-2008-02-139055

58. Rybtsov S, Ivanovs A, Zhao S, Medvinsky A (2016) Concealed expansion of immature precursors underpins acute burst of adult HSC activity in foetal liver. Dev 143:1284-1289. https ://doi.org/10.1242/dev.131193

59. Gordon-Keylock S, Sobiesiak M, Rybtsov S et al (2013) Mouse extraembryonic arterial vessels harbor precursors capable of maturing into definitive HSCs. Blood 122:2338-2345. https:// doi.org/10.1182/blood-2012-12-470971

60. de Bruijn MFTR (2000) Definitive hematopoietic stem cells first develop within the major arterial regions of the mouse embryo. EMBO J 19:2465-2474. https://doi.org/10.1093/ emboj/19.11.2465

61. Zhou F, Li X, Wang W et al (2016) Tracing haematopoietic stem cell formation at single-cell resolution. Nature 533:487492. https://doi.org/10.1038/nature17997

62. Kumano K, Chiba S, Kunisato A et al (2003) Notch1 but not Notch2 Is essential for generating hematopoietic stem cells from endothelial cells. Immunity 18:699-711. https://doi. org/10.1016/S1074-7613(03)00117-1

63. Robert-Moreno A (2005) $\mathrm{RBPj}$-dependent Notch function regulates Gata 2 and is essential for the formation of intraembryonic hematopoietic cells. Development 132:1117-1126. https://doi.org/10.1242/dev.01660

64. Uenishi GI, Jung HS, Kumar A et al (2018) NOTCH signaling specifies arterial-type definitive hemogenic endothelium from human pluripotent stem cells. Nat Commun 9:1828. https://doi. org/10.1038/s41467-018-04134-7

65. Villa N, Walker L, Lindsell CE et al (2001) Vascular expression of Notch pathway receptors and ligands is restricted to arterial vessels. Mech Dev 108:161-164. https://doi.org/10.1016/ S0925-4773(01)00469-5 
66. Yoon M-J, Koo B-K, Song R et al (2008) Mind bomb-1 Is essential for intraembryonic hematopoiesis in the aortic endothelium and the subaortic patches. Mol Cell Biol 28:4794-4804. https:// doi.org/10.1128/MCB.00436-08

67. Hadland BK, Huppert SS, Kanungo J et al (2004) A requirement for Notch1 distinguishes 2 phases of definitive hematopoiesis during development. Blood 104:3097-3105. https:// doi.org/10.1182/blood-2004-03-1224

68. Burns CE, Traver D, Mayhall E et al (2005) Hematopoietic stem cell fate is established by the Notch-Runx pathway. Genes Dev 19:2331-2342. https://doi.org/10.1101/gad.1337005

69. Bonkhofer F, Rispoli R, Pinheiro P et al (2019) Blood stem cellforming haemogenic endothelium in zebrafish derives from arterial endothelium. Nat Commun 10:1-14. https://doi.org/10.1038/ s41467-019-11423-2

70. Gama-Norton L, Ferrando E, Ruiz-Herguido C et al (2015) Notch signal strength controls cell fate in the haemogenic endothelium. Nat Commun 6:8510. https://doi.org/10.1038/ncomms9510

71. Zeng Y, He J, Bai Z et al (2019) Tracing the first hematopoietic stem cell generation in human embryo by single-cell RNA sequencing. Cell Res 29:881-894. https://doi.org/10.1038/s4142 2-019-0228-6

72. Watt SM, Butler LH, Tavian M et al (2000) Functionally defined CD164 epitopes are expressed on CD34+ cells throughout ontogeny but display distinct distribution patterns in adult hematopoietic and nonhematopoietic tissues. Blood 95:3113-3124. https:// doi.org/10.1182/blood.V95.10.3113

73. Hou S, Li Z, Zheng X et al (2020) Embryonic endothelial evolution towards first hematopoietic stem cells revealed by single-cell transcriptomic and functional analyses. Cell Res 30:376-392. https://doi.org/10.1038/s41422-020-0300-2

74. Boisset J-C, Clapes T, Klaus A et al (2015) Progressive maturation toward hematopoietic stem cells in the mouse embryo aorta. Blood 125:465-469. https://doi.org/10.1182/blood-2014-07588954

75. Baron CS, Kester L, Klaus A et al (2018) Single-cell transcriptomics reveal the dynamic of haematopoietic stem cell production in the aorta. Nat Commun 9:2517. https://doi.org/10.1038/ s41467-018-04893-3

76. Batsivari A, Rybtsov S, Souilhol C et al (2017) Understanding Hematopoietic stem cell development through functional correlation of their proliferative status with the intra-aortic cluster architecture. Stem Cell Reports 8:1549-1562. https://doi. org/10.1016/j.stemcr.2017.04.003

77. Howell ED, Speck NA (2020) Forks in the road to the first hematopoietic stem cells. Cell Res 30:457-458. https://doi. org/10.1038/s41422-020-0331-8

78. Zheng X, Zhang G, Gong Y et al (2019) Embryonic lineage tracing with Procr-CreER marks balanced hematopoietic stem cell fate during entire mouse lifespan. J Genet Genom 46:489-498. https://doi.org/10.1016/j.jgg.2019.10.005

79. Fares I, Chagraoui J, Lehnertz B et al (2017) EPCR expression marks UM171-expanded CD34+ cord blood stem cells. Blood 129:3344-3351. https://doi.org/10.1182/blood-2016-11-750729

80. Yvernogeau L, Gautier R, Petit L et al (2019) In vivo generation of haematopoietic stem/progenitor cells from bone marrowderived haemogenic endothelium. Nat Cell Biol 21:1334-1345. https://doi.org/10.1038/s41556-019-0410-6

81. Dieterlen-Lièvre F, Pouget C, Bollérot K, Jaffredo T (2006) Are Intra-Aortic Hemopoietic Cells Derived from Endothelial Cells During Ontogeny? Trends Cardiovasc Med 16:128-139. https:// doi.org/10.1016/j.tcm.2006.02.005

82. Jaffredo T, Gautier R, Brajeul V, Dieterlen-Lièvre F (2000) Tracing the progeny of the aortic hemangioblast in the avian embryo. Dev Biol 224:204-214. https://doi.org/10.1006/dbio.2000.9799
83. Yokomizo T, Dzierzak E (2010) Three-dimensional cartography of hematopoietic clusters in the vasculature of whole mouse embryos. Development 137:3651-3661. https://doi.org/10.1242/ dev.051094

84. Ciau-Uitz A, Walmsley M, Patient R (2000) Distinct origins of adult and embryonic blood in Xenopus. Cell 102:787-796. https ://doi.org/10.1016/S0092-8674(00)00067-2

85. Jaffredo T, Gautier R, Eichmann A, Dieterlen-lièvre F (1998) Intraaortic hemopoietic cells are derived from endothelial cells during ontogeny. Development 125:4575-4583

86. Taoudi S, Gonneau C, Moore K et al (2008) Extensive hematopoietic stem cell generation in the AGM region via maturation of VE-cadherin+CD45+ pre-definitive HSCs-Supplementary data. Cell Stem Cell 3:99-108. https://doi.org/10.1016/j. stem.2008.06.004

87. Souilhol C, Gonneau C, Lendinez JG et al (2016) Inductive interactions mediated by interplay of asymmetric signalling underlie development of adult haematopoietic stem cells. Nat Commun 7:1-13. https://doi.org/10.1038/ncomms 10784

88. North T, Gu TL, Stacy T et al (1999) Cbfa2 is required for the formation of intra-aortic hematopoietic clusters. Development 126:2563-2575

89. North TE, De Bruijn MFTR, Stacy T et al (2002) Runx1 expression marks long-term repopulating hematopoietic stem cells in the midgestation mouse embryo. Immunity 16:661-672. https:// doi.org/10.1016/S1074-7613(02)00296-0

90. Manaia A, Lemarchandel V, Klaine M et al (2000) Lmo2 and GATA-3 associated expression in intraembryonic hemogenic sites. Development 127:643-653

91. Bertrand JY, Giroux S, Golub R et al (2005) Characterization of purified intraembryonic hematopoietic stem cells as a tool to define their site of origin. Proc Natl Acad Sci 102:134-139. https ://doi.org/10.1073/pnas.0402270102

92. Wasteson P, Johansson BR, Jukkola T et al (2008) Developmental origin of smooth muscle cells in the descending aorta in mice. Development 135:1823-1832. https://doi.org/10.1242/dev.02095 8

93. Medvinsky A, Rybtsov S, Taoudi S, Glossary B (2011) Embryonic origin of the adult hematopoietic system: advances and questions. Development 138:1017-1031. https://doi.org/10.1242/ dev.040998

94. Lengerke C, Schmitt S, Bowman TV et al (2008) BMP and Wnt specify hematopoietic fate by activation of the Cdx-Hox pathway. Cell Stem Cell 2:72-82. https://doi.org/10.1016/J. STEM.2007.10.022

95. Pilon N, Oh K, Sylvestre JR et al (2007) Wnt signaling is a key mediator of Cdx1 expression in vivo. Development 134:23152323. https://doi.org/10.1242/dev.001206

96. Pilon N, Oh K, Sylvestre JR et al (2006) Cdx4 is a direct target of the canonical Wnt pathway. Dev Biol 289:55-63. https://doi. org/10.1016/j.ydbio.2005.10.005

97. Wang Y, Yabuuchi A, McKinney-Freeman S et al (2008) Cdx gene deficiency compromises embryonic hematopoiesis in the mouse. Proc Natl Acad Sci USA 105:7756-7761. https://doi. org/10.1073/pnas.0708951105

98. Choi K-D, Vodyanik M, Slukvin I (2011) Hematopoietic differentiation and production of mature myeloid cells from human pluripotent stem cells. Nat Protoc 6:296-313. https://doi.org/10.1038/ nprot.2010.184

99. Ditadi A, Sturgeon CM (2016) Directed differentiation of definitive hemogenic endothelium and hematopoietic progenitors from human pluripotent stem cells. Methods 101:65-72. https://doi. org/10.1016/j.ymeth.2015.10.001

100. Keller G, Kennedy M, Papayannopoulou T, Wiles MV (1993) Hematopoietic commitment during embryonic stem cell 
differentiation in culture. Mol Cell Biol 13:473-486. https://doi. org/10.1128/MCB.13.1.473.Updated

101. Vodyanik MA, Bork JA, Thomson JA et al (2005) Human embryonic stem cell-derived CD34+ cells: efficient production in the coculture with OP9 stromal cells and analysis of lymphohematopoietic potential. Blood 105:617-626. https://doi.org/10.1182/ blood-2004-04-1649

102. Lachmann N, Ackermann M, Frenzel E et al (2015) Largescale hematopoietic differentiation of human induced pluripotent stem cells provides granulocytes or macrophages for cell replacement therapies. Stem Cell Reports 4:282-296. https://doi. org/10.1016/j.stemcr.2015.01.005

103. Ledran MH, Krassowska A, Armstrong L et al (2008) Efficient hematopoietic differentiation of human embryonic stem cells on stromal cells derived from hematopoietic niches. Cell Stem Cell 3:85-98. https://doi.org/10.1016/j.stem.2008.06.001

104. Kennedy M, Awong G, Sturgeon CM et al (2012) T lymphocyte potential marks the emergence of definitive hematopoietic progenitors in human pluripotent stem cell differentiation cultures. Cell Rep 2:1722-1735. https://doi.org/10.1016/j.celre p.2012.11.003

105. Sturgeon CM, Ditadi A, Awong G et al (2014) Wnt signaling controls the specification of definitive and primitive hematopoiesis from human pluripotent stem cells. Nat Biotechnol 32:554561. https://doi.org/10.1038/nbt.2915

106. Doetschman TC, Eistetter H, Katz M et al (1985) The in vitro development of blastocyst-derived embryonic stem cell lines: formation of visceral yolk sac, blood islands and myocardium. Development 87:27-45

107. Irion S, Clarke RL, Luche $\mathrm{H}$ et al (2010) Temporal specification of blood progenitors from mouse embryonic stem cells and induced pluripotent stem cells. Development 137:2829-2839. https://doi.org/10.1242/dev.042119

108. Kennedy M, D'Souza SL, Lynch-Kattman M et al (2007) Development of the hemangioblast defines the onset of hematopoiesis in human ES cell differentiation cultures. Blood 109:2679-2687. https://doi.org/10.1182/blood-2006-09-047704

109. Lancrin C, Sroczynska P, Stephenson C et al (2009) The haemangioblast generates haematopoietic cells through a haemogenic endothelium stage. Nature 457:892-895. https://doi.org/10.1038/ nature 07679

110. Clarke RL, Yzaguirre AD, Yashiro-Ohtani Y et al (2013) The expression of Sox 17 identifies and regulates haemogenic endothelium. Nat Cell Biol 15:502-510. https://doi.org/10.1038/ ncb2724

111. Choi K, Kennedy M, Kazarov A et al (1998) A common precursor for hematopoietic and endothelial cells. Development 125:725-732. https://doi.org/10.1242/dev.00589

112. Guibentif C, Rönn RE, Böiers C et al (2017) Single-Cell Analysis Identifies Distinct Stages of Human Endothelial-to-Hematopoietic Transition. Cell Rep 19:10-19. https://doi.org/10.1016/j. celrep.2017.03.023

113. Creamer JP, Dege C, Ren Q et al (2017) Human definitive hematopoietic specification from pluripotent stem cells is regulated by mesodermal expression of CDX4. Blood. https://doi.org/10.1182/ blood-2016-11-749382

114. Ng ES, Azzola L, Bruveris FF et al (2016) Differentiation of human embryonic stem cells to HOXA+ hemogenic vasculature that resembles the aorta-gonad-mesonephros. Nat Biotechnol 34:1168-1179. https://doi.org/10.1038/nbt.3702

115. Lis R, Karrasch CC, Poulos MG et al (2017) Conversion of adult endothelium to immunocompetent haematopoietic stem cells. Nature 545:439-445. https://doi.org/10.1038/nature22326

116. Sugimura R, Jha DK, Han A et al (2017) Haematopoietic stem and progenitor cells from human pluripotent stem cells. Nature. https://doi.org/10.1038/nature22370
117. Pereira CF, Chang B, Qiu J et al (2013) Induction of a hemogenic program in mouse fibroblasts. Cell Stem Cell 13:205218. https://doi.org/10.1016/j.stem.2013.05.024

118. Gomes AM, Kurochkin I, Chang B et al (2018) Cooperative transcription factor induction mediates hemogenic reprogramming. Cell Rep 25:2821-2835.e7. https://doi.org/10.1016/j. celrep.2018.11.032

119. Notta F, Zandi S, Takayama N et al (2015) Distinct routes of lineage development reshape the human blood hierarchy across ontogeny. Science 351:1-16. https://doi.org/10.1126/ science.aab2116

120. Notta F, Doulatov S, Laurenti E et al (2011) Isolation of single human hematopoietic stem cells capable of long-term multilineage engraftment. Science (80-) 333:218-221. https://doi. org/10.1126/science.1201219

121. Gao X, Johnson KD, Chang Y-I et al (2013) Gata2 cis-element is required for hematopoietic stem cell generation in the mammalian embryo. J Exp Med 210:2833. https://doi.org/10.1084/ JEM.20130733

122. de Pater E, Kaimakis P, Vink CS et al (2013) Gata2 is required for HSC generation and survival. J Exp Med 210:2843-2850. https://doi.org/10.1084/jem.20130751

123. Kang H, Mesquitta W-T, Jung HS et al (2018) GATA2 Is dispensable for specification of hemogenic endothelium but promotes endothelial-to-hematopoietic transition. Stem Cell Reports 11:197-211. https://doi.org/10.1016/J.STEMC R.2018.05.002

124. Nottingham WT, Jarratt A, Burgess M, et al (2007) Runx1-mediated hematopoietic stem-cell emergence is controlled by a Gata/ Ets/SCL-regulated enhancer. https://doi.org/10.1182/blood

125. Batta K, Florkowska M, Kouskoff V, Lacaud G (2014) Direct reprogramming of murine fibroblasts to hematopoietic progenitor cells. Cell Rep 9:1871-1885. https://doi.org/10.1016/j.celre p.2014.11.002

126. Riddell J, Gazit R, Garrison BS et al (2014) Reprogramming committed murine blood cells to induced hematopoietic stem cells with defined factors. Cell 157:549-564. https://doi. org/10.1016/j.cell.2014.04.006

127. Sandler VM, Lis R, Liu Y et al (2014) Reprogramming human endothelial cells to haematopoietic cells requires vascular induction. Nature 511:312-318. https://doi.org/10.1038/nature13547

128. Kobayashi H, Butler JM, O’Donnell R et al (2010) Angiocrine factors from Akt-activated endothelial cells balance self-renewal and differentiation of haematopoietic stem cells. Nat Cell Biol 12:1046-1056. https://doi.org/10.1038/ncb2108

129. Meadows SM, Myers CT, Krieg PA (2011) Regulation of endothelial cell development by ETS transcription factors. Semin Cell Dev Biol 22:976-984. https://doi.org/10.1016/j.semcd b.2011.09.009

130. Kataoka H, Hayashi M, Nakagawa R et al (2011) Etv2 / ER71 induces vascular mesoderm from Flk1 + PDGFR $\alpha+$ primitive mesoderm Short title; Etv2 / ER71 induces vascular mesoderm. Blood 118:6975-6987. https://doi.org/10.1182/blood-2011-05352658

131. Wareing S, Eliades A, Lacaud G, Kouskoff V (2012) ETV2 expression marks blood and endothelium precursors, including hemogenic endothelium, at the onset of blood development. Dev Dyn 241:1454-1464. https://doi.org/10.1002/dvdy.23825

132. Lee D, Park C, Lee H et al (2008) ER71 acts downstream of BMP, notch, and Wnt signaling in blood and vessel progenitor specification. Cell Stem Cell 2:497-507. https://doi. org/10.1016/j.stem.2008.03.008

133. Ferdous A, Caprioli A, Iacovino $M$ et al (2009) Nkx2-5 transactivates the Ets-related protein 71 gene and specifies an endothelial/ endocardial fate in the developing embryo. Proc Natl Acad Sci USA 106:814-819. https://doi.org/10.1073/pnas.0807583106 
134. Morita R, Suzuki M, Kasahara H et al (2015) ETS transcription factor ETV2 directly converts human fibroblasts into functional endothelial cells. Proc Natl Acad Sci USA 112:160-165. https ://doi.org/10.1073/pnas.1413234112

135. Lange L, Hoffmann D, Schwarzer A et al (2019) Inducible forward programming of human pluripotent stem cells to hematoendothelial progenitor cells with hematopoietic progenitor potential. Stem cell reports. https://doi.org/10.1016/j.stemc r.2019.11.005

136. Wang K, Lin R, Hong X et al (2020) Robust differentiation of human pluripotent stem cells into endothelial cells via temporal modulation of ETV2 with modified mRNA. Sci Adv. https://doi. org/10.1101/2020.03.02.973289

137. Elcheva I, Brok-Volchanskaya V, Kumar A et al (2014) Direct induction of haematoendothelial programs in human pluripotent stem cells by transcriptional regulators. Nat Commun 5:1-11. https://doi.org/10.1038/ncomms5372

138. Vereide DT, Vickerman V, Swanson SA et al (2014) An expandable, inducible hemangioblast state regulated by fibroblast growth factor. Stem cell reports 3:1043-1057. https://doi.org/10.1016/j. stemcr.2014.10.003

139. Park MA, Kumar A, Jung HS et al (2018) Activation of the arterial program drives development of definitive hemogenic endothelium with lymphoid potential. Cell Rep 23:2467-2481. https://doi.org/10.1016/j.celrep.2018.04.092

140. Tan YT, Ye L, Xie F et al (2018) Respecifying human iPSCderived blood cells into highly engraftable hematopoietic stem and progenitor cells with a single factor. Proc Natl Acad Sci USA 115:2180-2185. https://doi.org/10.1073/pnas.1718446115

141. Milne TA, Briggs SD, Brock HW et al (2002) MLL targets SET domain methyltransferase activity to Hox gene promoters. Mol Cell 10:1107-1117. https://doi.org/10.1016/S1097 -2765(02)00741-4

142. Jude CD, Climer L, Xu D et al (2007) Unique and independent roles for MLL in adult hematopoietic stem cells and progenitors. Cell Stem Cell 1:324-337. https://doi.org/10.1016/J. STEM.2007.05.019

143. Sauvageau G, Thorsteinsdottir U, Eaves CJ et al (1995) Overexpression of HOXB4 in hematopoietic cells causes the selective expansion of more primitive populations in vitro and in vivo. Genes Dev 9:1753-1765. https://doi.org/10.1101/gad.9.14.1753

144. Kyba M, Perlingeiro RCR, Daley GQ (2002) HoxB4 confers definitive lymphoid-myeloid engraftment potential on embryonic stem cell and yolk sac hematopoietic progenitors. Cell 109:2937. https://doi.org/10.1016/S0092-8674(02)00680-3

145. Kitajima K, Minehata K, Sakimura K et al (2014) In vitro generation of HSC-like cells from murine ESCs / iPSCs by enforced expression of LIM-homeobox transcription factor Lhx2 In vitro generation of HSC-like cells from murine ESCs / iPSCs by enforced expression of LIM-homeobox transcription factor Lhx2. Blood 117:3748-3758. https://doi.org/10.1182/blood-2010-07298596
146. Wang L, Menendez P, Shojaei F et al (2005) Generation of hematopoietic repopulating cells from human embryonic stem cells independent of ectopic HOXB4 expression. J Exp Med 201:1603-1614. https://doi.org/10.1084/jem.20041888

147. Teichweyde N, Kasperidus L, Carotta S et al (2018) HOXB4 promotes hemogenic endothelium formation without perturbing endothelial cell development. Stem Cell Rep 10:875-889. https ://doi.org/10.1016/j.stemcr.2018.01.009

148. Alharbi RA, Pettengell R, Pandha HS, Morgan R (2013) The role of HOX genes in normal hematopoiesis and acute leukemia. Leukemia 27:1000-1008. https://doi.org/10.1038/leu.2012.356

149. Moens CB, Selleri L (2006) Hox cofactors in vertebrate development. Dev Biol 291:193-206. https://doi.org/10.1016/J.YDBIO .2005 .10 .032

150. Sauvageau G, Lansdorp PM, Eaves CJ et al (1994) Differential expression of homeobox genes in functionally distinct CD34+ subpopulations of human bone marrow cells. Proc Natl Acad Sci USA 91:12223-12227. https://doi.org/10.1073/pnas.91.25.12223

151. Dou DR, Calvanese V, Sierra MI et al (2016) Medial HOXA genes demarcate haematopoietic stem cell fate during human development. Nat Cell Biol 18:595-606. https://doi.org/10.1038/ ncb3354

152. Lawrence HJ, Christensen J, Fong S et al (2005) Loss of expression of the Hoxa-9 homeobox gene impairs the proliferation and repopulating ability of hematopoietic stem cells. Blood 106:3988-3994. https://doi.org/10.1182/blood-2005-05-2003

153. Magnusson M, Brun ACM, Lawrence HJ, Karlsson S (2007) Hoxa9/hoxb3/hoxb4 compound null mice display severe hematopoietic defects. Exp Hematol 35:1421.e1-1421.e9. https://doi. org/10.1016/J.EXPHEM.2007.05.011

154. Ramos-Mejía V, Navarro-Montero O, Ayllón V et al (2014) HOXA9 promotes hematopoietic commitment of human embryonic stem cells. Blood 124:3065-3075. https://doi.org/10.1182/ blood-2014-03-558825

155. Doulatov S, Vo LTT, Chou SSS et al (2013) Induction of multipotential hematopoietic progenitors from human pluripotent stem cells via respecification of lineage-restricted precursors. Cell Stem Cell 13:459-470. https://doi.org/10.1016/j. stem.2013.09.002

156. Vo LT, Kinney MA, Liu X et al (2018) Regulation of embryonic haematopoietic multipotency by EZH1. Nature. https://doi. org/10.1038/nature25435

157. Wahlster L, Daley GQ (2016) Progress towards generation of human haematopoietic stem cells. Nat Cell Biol 18:1111-1117. https://doi.org/10.1038/ncb3419

Publisher's Note Springer Nature remains neutral with regard to jurisdictional claims in published maps and institutional affiliations. 